\title{
Analysis of the Implementation of the Primary and/or Inertial Frequency Control in Variable Speed Wind Turbines in an Isolated Power System with High Renewable Penetration. Case Study: El Hierro Power System
}

\author{
Guillermo Martínez-Lucas ${ }^{1, *} \mathbb{C}$, José Ignacio Sarasúa ${ }^{1}$, Juan Ignacio Pérez-Díaz ${ }^{1}{ }^{(0)}$, \\ Sergio Martínez ${ }^{2}$ (D) and Danny Ochoa ${ }^{2}$ (D) \\ 1 Department of Hydraulic, Energy and Environmental Engineering, Universidad Politécnica de Madrid, \\ C/Profesor Aranguren 3, 28040 Madrid, Spain; joseignacio.sarasua@upm.es (J.I.S.); ji.perez@upm.es (J.I.P.-D.) \\ 2 Department of Automation, Electrical Engineering and Electronics, and Industrial Informatics, \\ ETSI-Industriales, Universidad Politecnica de Madrid, C/Jose Gutierrez Abascal, 2, 28006 Madrid, Spain; \\ sergio.martinez@upm.es (S.M.); danny.ochoac@alumnos.upm.es (D.O.) \\ * Correspondence: guillermo.martinez@upm.es; Tel.: +34-910674333
}

Received: 26 April 2020; Accepted: 27 May 2020; Published: 28 May 2020

check for updates

\begin{abstract}
With high levels of wind energy penetration, the frequency response of isolated power systems is more likely to be affected in the event of a sudden frequency disturbance or fluctuating wind conditions. In order to minimize excessive frequency deviations, several techniques and control strategies involving Variable Speed Wind Turbines (VSWTs) have been investigated in isolated power systems. In this paper, the main benefits and disadvantages of introducing VSWTs-both their inertial contribution and primary frequency regulation-in an exclusively renewable isolated power system have been analyzed. Special attention has been paid to the influence of the delays of control signals in the wind farm when VSWTs provide primary regulation as well as to the wind power reserve value which is needed. To achieve this objective, a methodology has been proposed and applied to a case study: El Hierro power system. A mathematical dynamic model of the isolated power system, including exclusively renewable technologies, has been described. Representative generation schedules and wind speed signals have been fixed according to the observed system. Finally, in order to obtain conclusions, realistic system events such as fluctuations in wind speed and the outage of the generation unit with the higher assigned power in the power system have been simulated.
\end{abstract}

Keywords: isolated power system; frequency regulation; variable speed wind turbine; primary frequency regulation; inertia emulation

\section{Introduction}

The increase in the penetration of renewable energy for electricity generation is a reality in the vast majority of countries, both in Europe and in the rest of the world. In fact, this constitutes a good way to reduce the fossil fuel dependence and greenhouse gas emissions [1]. Solar and wind-based generation systems have become sustainable and environmentally friendly options to supply power to isolated or off-grid locations, i.e., islands [2].

In recent years, the use of renewable energy sources to displace fossil fuels in small isolated systems has received considerable attention [3]. This fact has taken place largely because of the existing synergies between wind generators and Pumped Storage Hydropower Plants (PSHPs). Some remarkable works developed on the Aegean Islands analyze these synergies [4,5]. In the case 
of the Faroe Islands, [6] analyzed the wind power integration combined with a variable speed PSHP. Many studies also focus on increasing the penetration of renewable energies (wind-hydro systems) in the Canary Islands [7,8]. In fact, El Hierro island aims to become $100 \%$ free from carbon dioxide emissions [9].

With high levels of wind energy penetration, especially with the large amount of Variable Speed Wind Turbines (VSWTs) incorporated into the modern utility grids, the frequency response of power systems is more likely to be affected in the event of a sudden frequency disturbance or fluctuating wind speed conditions [10]. In general, the renewable energy impact on power systems mainly depends on their penetration rate and the system inertia [11]. For this reason, the negative effects of renewable energy sources are amplified in isolated systems. In addition to its small size, the vast majority of renewable power generation technologies (except conventional hydro power plants and fixed speed wind turbines) are decoupled from the grid through a power electronic converter, implying a considerable lack of inertia in the power system [12]. For this reason, many studies analyze the impact on the frequency regulation of the penetration of renewable energies in isolated systems [13].

In order to minimize the excessive frequency deviations, several techniques and strategies involving renewable power generation technologies (mainly VSWTs) have been investigated in isolated power systems. According to [14], VSWTs can provide inertial response and primary and secondary regulation.

VSWTs' inertial contribution consists of adding an auxiliary signal sensitive to frequency (actually, sensitive to the Rate of Change of Frequency (RoCoF)) to the reference power set point in VSWTs-for example, momentarily increasing wind turbine output power in the case of a frequency reduction. This momentary wind power increment implies a reduction in the VSWTs' rotor speed that is corrected by the Maximum Power Point Tracking (MPPT) control [15]. Several studies are focused on the VSWTs' conventional inertial contribution to frequency regulation [16,17]. These studies introduce the inertial action as a derivative controller monitoring the frequency error. To improve the use of variable-speed wind energy conversion systems, the conventional inertial control loop can be modified by adding a proportional loop that weights the frequency deviation, thus obtaining a Proportional-Derivative (PD) control [18]. This control loop has been later used in [19].

VSWTs' primary frequency regulation (R1) can provide energy to assist in reducing frequency deviation, raising the frequency nadir for a given loss of supply and stabilizing the system frequency. In fact, most VSWT manufacturers now include primary frequency response capabilities as part of their offerings [20]. As for conventional power plants, the proposed control strategy requires VSWTs to preserve a power margin, so a non-optimal working point is reached in the response curve of torque versus the rotor speed of the turbine [21]. Trying to reduce this wind spill, Cortecuise et al. proposed a strategy to allow maintaining a regular reserve only when the wind turbine generator works at full load [22]. For it, a very simple system composed only of one power generator, three wind turbines and two loads was considered. The possibility to participate in R1 with a VSWT is analyzed with the help of experiments on a test bench in Reference [23]. Since only the VSWT dynamics are considered, artificial frequency variations in step form are used as the model input. Authors recognized that one of the R1 limitations was that the value of the reference power must be determined a priori. Ma and Chowdhury developed a pitch angle control—which is similar to the governor control of a synchronous machine - to provide wind plant frequency regulation capability [24]. In this case, the wind speed was assumed constant while the model input is a variation in the power demand. The assumed system consists of a synchronous generator, a VSWT and a load demand.

The implementation of both control actions together has been investigated too. Margaris et al. analyzed the expected benefits and drawbacks of each regulation strategy [25]. These authors selected as a case study the power system of Rhodes Island, which is equipped not only with VSWTs but also with one gas turbine, two steam turbines and two diesel generators, whose synchronous generators inertia smooths the frequency deviations. Wang et al. included a limitation on the rate of change of VSWT electrical power to avoid fast variations in the turbine power output and reduce mechanical 
stresses [26]. The authors concluded that combining both inertial and primary frequency controllers improved the frequency behavior. However, they recognized as a limitation the brevity of the dynamic simulations carried out (about one minute), because they were not sufficient to characterize the reliability of the wind primary reserve. Wang and Wu proposed a distributed cooperation framework in order to improve the control efficiency for a doubly fed induction generator-based wind farm to participate in primary frequency regulation jointly with several thermal plants, including inertia emulation and droop characteristics similar to conventional plants [27].

Many times, authors do not pay special attention to the implementation of the different VSWTs control loops in the wind farms. To the authors' knowledge, only Feltes et al. take into account the existence of communication delay between the frequency measurement and the primary control action [20]. Nevertheless, in the mentioned study, the influence of the control action delay on the dynamic response is not analyzed.

The main objective of this paper is to present a methodology to analyze the main benefits and disadvantages of introducing different control strategies in the VSWTs in an exclusively renewable isolated power system, taking into account the influence of the delays of control signals in the wind farm and the primary reserve. The proposed analysis, based on simulation results, is delivered in terms of frequency regulation, efficiency and energy indices. The isolated power system will be equipped with VSWTs, hydroelectric units, and a pump station. Hydroelectric units and the pump station are aimed to provide both primary and secondary regulation. To achieve this objective, a mathematical model including a hydropower plant, a pump station equipped with Variable Speed Pumps (VSPs) and Fix Speed Pumps (FSPs), a wind farm, the Automatic Generation Control (AGC), the power system and the power demand sensitive to the frequency deviation has been proposed. The usefulness of the results obtained from the simulations carried out with this model lies in the credibility of the simulation scenarios. The vast majority of the studies mentioned above do not include a wide variety of scenarios that enable the testing of the VSWTs' contribution to frequency regulation. Therefore, enough representative generation schedules according to the observed system demand and wind power generation were defined. Furthermore, realistic system events that involve frequency deviations such as fluctuation in the wind speed and the outage of the generation unit with the higher assigned power have been recommended. The proposed methodology extracted from this study is applied to the El Hierro power system. El Hierro is an island in the Canary Islands archipelago. The island aims to become entirely free from greenhouse gases emissions due to a pumped storage power plant and a wind farm committed in 2014 [9].

Therefore, the main contributions of this paper are: (i) the analysis of the main benefits and disadvantages in terms of the energy, efficiency and frequency regulation of introducing different control strategies to the VSWTs in an exclusively renewable isolated power system; (ii) the consideration in said analysis of the influence of the control signal delays in the wind farm; and (iii) the generation of representative generation schedules according to the observed system demand and wind power generation.

The paper is organized as follows: In Section 2, the dynamic model is presented. The power-frequency control is described in Section 3. In Section 4, the followed methodology for generating the simulation scenarios is defined. In Section 5, some realistic events are simulated considering the proposed simulation scenarios applied to El Hierro power system. Finally, Section 6 outlines the main conclusions of this study.

\section{Dynamic Model}

A sufficiently detailed mathematical model has been designed to analyze the implementation of the primary and inertial regulation of VSWTs in an isolated power system like the one shown in Figure 1a. This isolated system, and consequently the model developed in Matlab Simulink [8] that is shown in Figure 1b, is composed of a hydropower plant, a pump station equipped with VSPs and FSPs, a wind farm, the Automatic Generation Control (AGC), the power system and the power demand 
sensitive to frequency deviation. The power lines' dynamics are ignored as their influence on the frequency system is not significant [28]. The electromagnetic transients and pump station converter dynamics are supposed to be much faster than the other components of the model, so their influence in the system's dynamics can be also omitted [29].

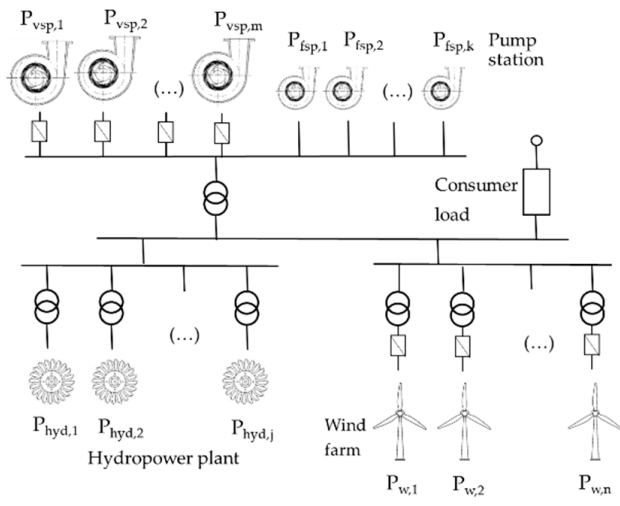

(a)

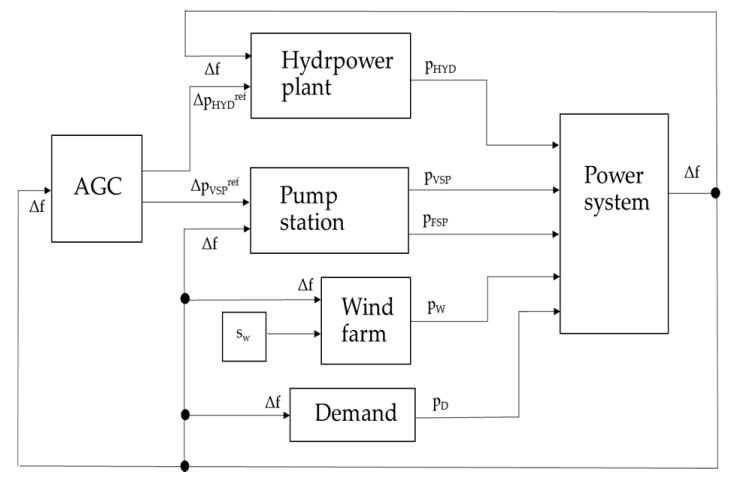

(b)

Figure 1. (a) Power system simplified one-line diagram and (b) dynamic model block diagram.

An aggregated inertial model is used for reproducing system frequency deviations because of the reduced size of the analyzed isolated power system [30]. This approximation has been successfully used by authors in the El Hierro power system [19] and by O'Sullivan et al. in the Irish one [13]. In this assumed power system, frequency deviations are the consequence of the imbalance between the power supplied by the generation units (i.e., hydroelectric units $\left(p_{h y d}\right)$ and wind turbines $\left.\left(p_{w}\right)\right)$ and the power demand (i.e., VSPs $\left(p_{v s p}\right)$, FSPs $\left(p_{f s p}\right)$ and the consumers' loads $\left(p_{d e m}\right)$, which include both the under frequency load-shedding scheme and their sensitivity to frequency variations through the $D_{\text {net }}$ term). Frequency variations are formulated in Equation (1).

$$
f \frac{d f}{d t}=\frac{1}{T_{m, h y d}(t)}\left(p_{h y d}+p_{w}-p_{v s p}-p_{f s p}-p_{d}-D_{n e t} \cdot \Delta f\right)
$$

where $T_{m, h y d}(t)$ corresponds to the mechanical starting time of the hydroelectric units and depends on the number of units operating at each moment. Note that only the hydroelectric units provide system inertia because the FSPs, VSPs and VSWTs are connected to the grid through frequency converters.

For introducing the hydropower plant and pump station dynamic response in the model, the authors suggest models previously developed and satisfactorily used [19]. The proposed wind turbine model, which includes the wind power model and both pitch and torque MPPT control, is extracted from [31]. For the rotor mechanical model, a one-mass rotor model is used, which is enough according to [32] in cases where the power converter decouples the generator from the grid.

Finally, a load shedding scheme is added to the model as, in an isolated power system with a high penetration of renewable energies, frequency deviations may overpass thresholds associated with damage in both generating and demand equipment. This load-shedding scheme is based on the conventional Under Frequency Load Shedding (UFLS) scheme, but the RoCoF has been added as a complementary input.

\section{Power-Frequency Control}

The frequency control is divided into two sequential actions: primary and secondary regulation. This control scheme is assumed by many power systems in Europe. Frequency error, which is a consequence of the imbalance between power generation and power demand, is corrected initially by hydroelectric units and VSPs according to their respective droops. VSWTs are incorporated into primary regulation including different control action delays in order to analyze the effect of their 
contribution. Moreover, the inertial frequency regulation developed by VSWTs is also added in this analysis.

Permanent frequency error resulting after the action of the primary frequency control loop is rectified by secondary regulation, which is coordinated by the AGC. The AGC continuously sends increments of power reference to hydroelectric units and VSPs. The control schemes of hydroelectric units, VSPs and VSWTs are described in the following sections.

\subsection{Hydroelectric Units Control Loop}

The governor model of the hydroelectric units used in this study is shown in Figure 2a and based on [33]. This controller monitors both the system frequency and load through the feedback signals of the frequency error and power variation. This control loop also includes the power reference provided by the AGC. The action of this governor allows eliminating the power-frequency error under electrical load variations. The error signal is processed by a conventional proportional-integral (PI) controller, producing a change in the wicket gate position. The limits in the gate position as well as its rate of change are considered in the model.

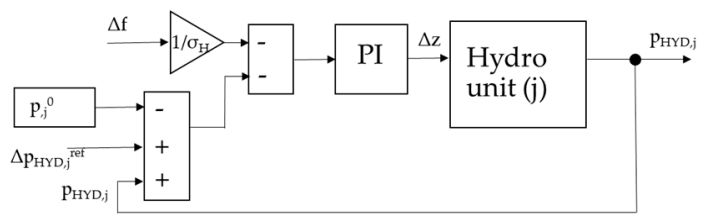

(a)

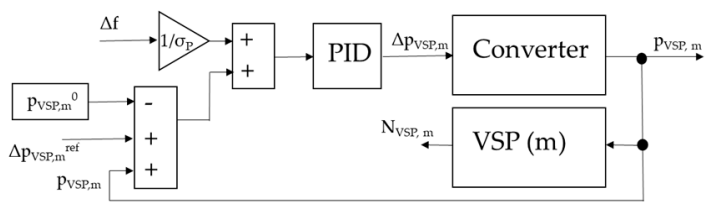

(b)

Figure 2. Block diagram of hydro units (a) and Variable Speed Pumps (VSPs) (b) control loop.

\subsection{Variable Speed Pumps Control Loop}

The power consumed by the pump station can be modified to contribute to frequency regulation. As shown in Figure 2b, the VSP controller consists of a PID controller that modifies the power reference to be tracked by the converter from the frequency error and the power variation. Analogously to the hydroelectric units, this control loop includes the power reference provided by the AGC. The PI controller component proposed in [19] ensures that permanent frequency errors are corrected. The derivative component of the controller represents the synthetic inertia provided by the VSPs. Note that the pumps are connected to the system through a power converter, so inertial behavior must be emulated through the derivative component. The power converters change the electric power consumption by VSPs, reducing the frequency deviation. Therefore, the VSP rotor speed and mechanical power will adapt to the new electrical power.

\subsection{Secondary Control Loop}

This control action is proposed to be modelled in a similar way to [34]. Thus, the total secondary regulation effort is obtained from (2). $K_{f}$ has been estimated according to the ENTSO-E recommendations. This regulation effort is distributed among all the hydroelectric units and VSPs that are synchronized as a function of their participation factors $K_{u, i}$ from (3) and (4). Therefore, the sum of all the participation factors will be equal to one (5). It is assumed that all the units connected to the power system participate in secondary regulation control and the participation factors have been obtained as a function of the speed droop of each unit [35].

$$
\begin{gathered}
\Delta R R=-\Delta f \cdot K_{f}, \\
\Delta p_{H Y D, j}{ }^{r e f}=\frac{1}{T_{u, H Y D}} \int \Delta R R \cdot K_{u, H Y D, j} d t, \\
\Delta p_{V S P, m}{ }^{r e f}=\frac{1}{T_{u, V S P}} \int \Delta R R \cdot K_{u, V S P, m} d t,
\end{gathered}
$$




$$
\sum K_{u}=\sum_{1}^{j} K_{u, H Y D, j}+\sum_{1}^{m} K_{u, V S P, m}=1
$$

\subsection{Variable Speed Wind Turbines Control Loops}

VSWTs can provide both inertial and primary frequency regulation. Figure 3 shows both the inertial and primary frequency regulation control loops of a complete wind farm. Inertial frequency regulation consists of adding an auxiliary power signal obtained from frequency variations to the reference power set point in VSWTs through a PD controller (see Equation (6)). This control action is delivered by each VSWT individually, so it is assumed that the power signal provided to the converter takes place at the same moment that the signal error is measured. The proportional component of the controller acts as a fast frequency response, monitoring the frequency deviation, while the derivative component emulates the inertial response by monitoring the RoCoF value $[18,36]$. For example, in response to a frequency decrease, that implies increasing the wind turbine output power momentarily from the kinetic energy stored in the rotational masses. Consequently, the rotor speed slows down (the power injected into the grid is higher than the power extracted from the wind).

$$
\Delta p_{\text {iner }}=\left[K_{\text {,iner }}+K_{d, \text { iner }} \frac{d f}{d t}\right]\left(f_{\text {ref }}-f\right) \text {. }
$$

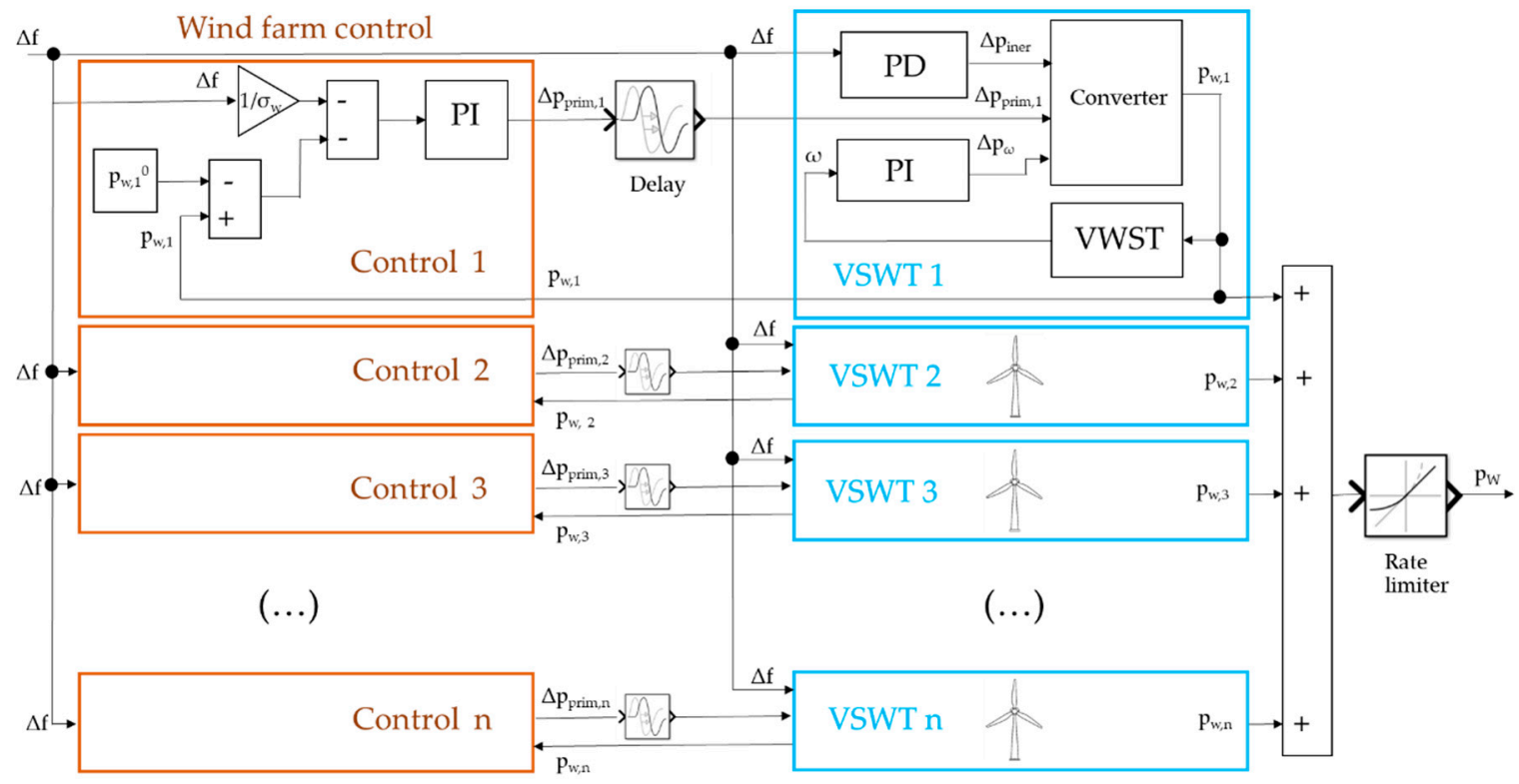

Figure 3. Frequency control scheme of wind farm and variable speed wind turbines.

The generator torque control allows variation in the VSWT rotor speed, following a MPPT strategy for extracting as much power as possible from the wind flow [37]. The reference value is the rotational speed (Equation (8)), as described in expression (7) according to [31]. This power signal is also added to be tracked by the power converter. This control loop also restores the rotational speed after the inertial controller acts, so that the power injected from the VSWT converter is smaller than the extracted wind power.

$$
\Delta p_{\omega}=\omega\left[K_{p \omega}+K_{i \omega} \int d t\right]\left(\omega-\omega_{r e f}\right) .
$$

Regarding primary frequency regulation, VSWTs are able to correct both the system frequency and the supplied electric power errors analogously to hydroelectric units through a PI controller whose control action consists of a power signal to be tracked by the power converter. The power reference is constant, matching the initial assigned wind power $[23,24]$. In this way, VSWTs are not able to make 
use of all the available wind energy, as this control loop introduces a power reduction if the wind power supplied grows with respect to the initial value as a consequence of an increment in the wind speed. Nevertheless, this implies that the power supplied by hydroelectric units is nearer to the initial one, therefore avoiding power deviations with respect to the programmed power.

If VSWTs contribute to primary frequency regulation, a wind power reserve is needed. In this case, the de-loading through rotational overspeed control has been used, achieving a non-optimal working point in the power-rotor speed curve of the turbine [21] as formulated in Equation (8).

$$
\omega_{r e f}=-0.75\left(\frac{p_{w, n}}{1-r}\right)^{2}+1.59\left(\frac{p_{w, n}}{1-r}\right)+0.63
$$

where $r$ represents the unitary proportion of the wind power reserve. For example, $r=0.10$ implies that the rotational speed is reduced so that the electric power supplied by VSWT, $p_{w, n}$, is $10 \%$ lower than the power available from the wind.

Finally, a limitation in the rate of change of the wind farm electrical power has been introduced in the model [15]. From the point of view of VSWTs, it reduces mechanical stress [26] and, from the point of view of the system operator, sudden changes in the wind speed do not translate into strong frequency deviations.

The measurement of the controlled variables, power of each VSWT and system frequency, and estimation of the primary response signal take place in the control center of the wind farm. Because of that fact, the model includes a time delay that represents the time spent by the control action to travel from the control center to each VSWT. This delay may vary depending on the way the SCADA system interfaces with the turbine manufacturer's park controller [20]. In this sense, the time delay depends on the type of VSWT: Type 3 (doubly fed induction machine) or Type 4 (full converter).

Therefore, the total power supplied by a VSWT power converter corresponds to the sum of the initial power supplied and the increments obtained from both the inertial and primary frequency regulation control loops and the VSWT speed control loop. Finally, the power supplied by the wind farm will be the sum of each VSWT's supplied power, as in Equation (9).

$$
p_{w}=\sum_{i=1}^{n}\left(p_{w, i}{ }^{0}+\Delta p_{\text {iner }, i}+\Delta p_{\omega, i}+\Delta p_{p r i m, i}\right)
$$

\section{Methodology for Generating Simulation Scenarios}

The main objective of this paper is to analyze the main benefits and disadvantages of introducing different control strategies to the VSWTs in an isolated power system, paying special attention to the influence of the delays in control signals in the wind farm. The usefulness of the results obtained from the simulations carried out with the model described in above sections lies in the credibility of the simulation scenarios. These scenarios are composed of two different parts.

The first one consists in defining enough representative generation schedules according to the observed power demand and wind power generation in the system. The second one comprises generating realistic system events that involve frequency deviations, allowing the comparison of the different control strategies. In this case, in a $100 \%$ renewable generation situation two different events have been considered: the fluctuation in the wind speed and the outage of the generation unit with the highest assigned power.

\subsection{Definition of Representative 100\% Renewable Generation Schedules}

For the definition of representative schedules, a study of the power system demand is needed, and recorded data may be very helpful. Several demand levels can be identified and associated with a percentage of occurrence. In the same way, it is interesting to collect and analyze wind power data. These indicators can be obtained from the existing wind turbines or can be the result of future planned wind farms. 
The combination of different system demands and wind power levels results in several net demands that need to be covered by a combination of hydroelectric units, VSPs and FSPs-i.e., a generation schedule. Several rules are proposed for selecting the number of components and their initial powers. Some of them are inspired in [38].

- $\quad$ No diesel units are scheduled.

- The same initial power is assigned to all hydroelectric units.

- The same initial power is assigned to all VSPs.

- The global upward reserve of the system, obtained from the sum of the reserves of each hydroelectric unit, VSP and VSWT when they provide primary regulation, must be higher than (i) the power of the unit with the highest assigned power, the so-called N-1 criteria; or (ii) the deepest predicted ramp of wind power.

- The global downward reserve is $50 \%$ of the upward reserve.

- The wind power is limited so that the system downward reserve would not ever be overpassed.

- The minimal number of pumps, compatible with the other rules, is programmed.

- VSPs are the first pumps that are scheduled.

\subsection{Generation of Representative Variable Wind Speed Signals}

For each of the scenarios under consideration, the response of the power system to the fluctuating speed of the wind incoming to the wind power plant is tested. Thus, the main input variable to the system is the wind speed, $s_{w}$, as shown in Figure $1 \mathrm{~b}$. As a consequence, an adequate simulation of its evolution is crucial, particularly in, but not limited to, the short term. However, wind speed fluctuations are highly dependent on atmospheric conditions and specific site characteristics, what makes their modeling difficult.

In general, wind speed can be modeled as a spatial distribution in three directions, but, assuming that the area swept by the blades of a turbine is normal to the wind direction, the model only requires a one-dimensional component. There are various alternatives for modeling the horizontal component of wind speed. Probability distributions that are useful for the estimation of energy production, like the Weibull distribution, can give approximate results. More realistic results can be obtained with Van der Hoven's model [39] for the medium and long term, and with von Karman's turbulence model [40] for the short term.

In the time frame of primary frequency control—the one under consideration in this workthe relevant wind speed spectrum must include both medium- and long-term fluctuations and turbulence components. Thus, a more adequate model for the wind speed numerical generator is the hybrid one proposed in [41], where the time series of wind speeds, $s_{w}(t)$, can be computed by addition of a medium- and long-term component, $s_{w m l}(t)$, and a turbulence component, $s_{w t}(t)$ (Equation (10)).

$$
s_{w}(t)=s_{w m l}(t)+s_{w t}(t) .
$$

The medium- and long-term component can be calculated with a sample period $T_{s m l}$ according to Van der Hoven's model, as shown in Equation (11).

$$
s_{w m l}(t)=\overline{s_{w}}+\sum_{i=1}^{N} A_{i} \cos \left(\omega_{i} t+\varphi_{i}\right)
$$

This equation is limited to $N=30$, with uniformly distributed random phase $\varphi_{i}$ in the interval $[-\pi, \pi]$, and with amplitudes obtained according to the expression (12):

$$
A_{i}=\frac{\sqrt{2 \cdot\left[S_{s s}\left(\omega_{i}\right)+S_{s s}\left(\omega_{i+1}\right)\right] \cdot\left(\omega_{i+1}-\omega_{i}\right)}}{\pi}
$$


This equation is sampled with discrete angular frequencies $\omega_{i}=2 \pi \cdot f_{i} / 3600$, where $f_{i}$ is the $i$ th element of the following vector of frequencies: $f=[0.001,0.002,0.003,0.004,0.005,0.006,0.007$, $0.008,0.009,0.01,0.02,0.03,0.04,0.05,0.06,0.07,0.08,0.09,0.1,0.2,0.3,0.4,0.5,0.6,0.7,0.8,0.9,1,2$, 3] cycles/h [41], and $S_{s s}\left(\omega_{i}\right)$ are the corresponding values of the power spectral density. These can be obtained from the power spectrum of expression (13):

$$
S_{s s}\left(\omega_{i}\right)=0.475 \frac{\sigma^{2} L}{\overline{s_{w}}}\left[1+\left(\frac{\omega_{i} L}{\overline{s_{w}}}\right)^{2}\right]^{-\frac{5}{6}},
$$

where the wind farm site is characterized by the length scale, $L$, and the turbulence intensity, $\sigma$, which can be estimated from [42].

For the $i$ th period of the medium- and long-term component of the wind speed, $s_{w m l}(t)$ is constant and equal to $s_{w m l}\left(i \cdot T_{s m l}\right)$, and the turbulent component can be calculated with a sample period $T_{s t}$ (a fraction of $T_{\text {sml }}$ ), as shown in Equation (14):

$$
s_{w t}(t)=k_{\sigma, s} \cdot \overline{s_{w}} \cdot n_{\mathcal{c}}(t),
$$

where $k_{\sigma, s}$ is the experimental slope of the regression describing the relation between the mean value of $s_{w}$ and the estimated value of the standard deviation. $n_{c}(t)$ is the output colored noise of a filter driven by white Gaussian noise with power $0 \mathrm{~dB}$, according to a variant of the procedures described in [41] in which the filter transfer function for the $i$ th period is approximated by expression (15):

$$
H(s)=K_{F}+\frac{\left(0.4 T_{F} s+1\right)}{\left(T_{F} s+1\right)\left(0.25 T_{F} s+1\right)},
$$

where $T_{F}=L / s_{w m l}\left(i \cdot T_{s m l}\right)$ and $K_{F}=\left[2 \pi / B(0.5,1 / 3) T_{F} / T_{s t}\right]^{0.5}$, where $B$ is the beta function.

\section{Case Study: El Hierro Power System}

El Hierro is an island that belongs to the Canary Islands archipelago. The UNESCO declared the island as a biosphere reserve in 2000. From the energy point of view, the main task of this isolated power system is to minimize the use of fossil fuels. Traditionally, diesel groups (15 MW) covered the demand of the island (a 7.7 MW peak and a 2.1 MW valley in 2018). Thus, in 2014 Gorona del Viento Wind Pumped storage power plant was commissioned-see Figure 4. The wind farm is formed of five 2.3 MW ENERCON E-70 VSWTs (type 4), and the pumped storage power plant is equipped with $4 \times 2.8$ MW Pelton turbines, $6 \times 0.5$ MW FSPs and $2 \times 1.5$ MW VSPs. The main data and characteristics of the system that define the dynamic model are reported in [19].

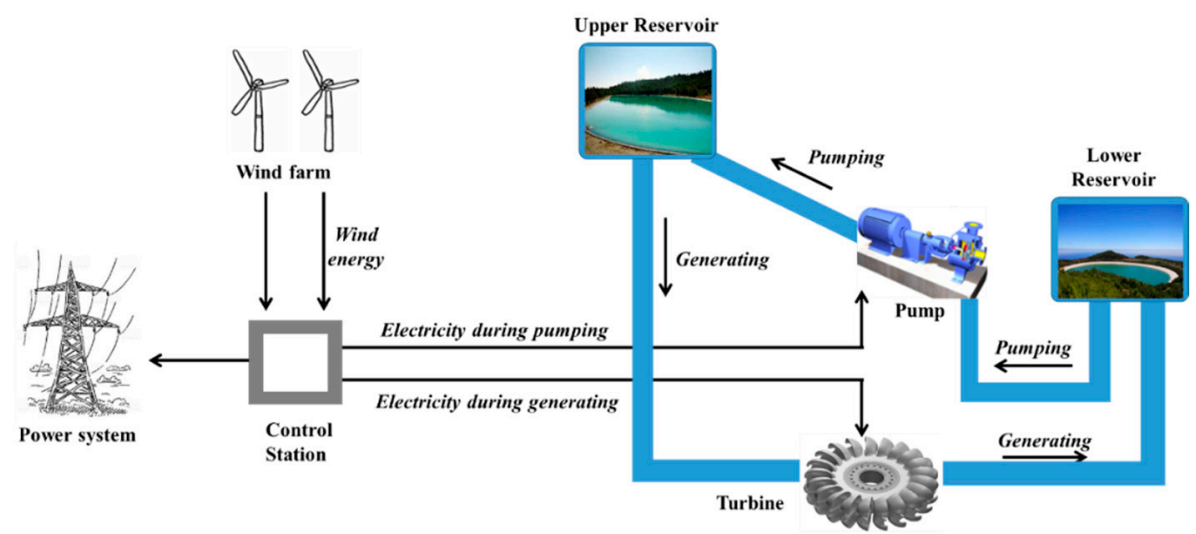

Figure 4. Gorona del Viento Wind-Hydro power plant. 
In the last two years, the participation of renewable energy has grown significantly. In the summer of 2019, for 596 consecutive hours the electric demand was continuously and exclusively supplied by renewable energy resources. However, this significant milestone presents an important operational disadvantage - the difficulty in controlling the power system frequency due to wind power variations. This problem is aggravated by the lack of system inertia, inherent in VSWTs connected to the system through power electronic equipment, so that load shedding is a common practice, especially when using FSPs [43]. In this context, the contribution of VSWTs to frequency regulation becomes an important means to respond to the challenge of a generation $100 \%$ free of greenhouse gas emissions. In spite of the pump station, the hydropower plant and VSWTs' contribution to frequency regulation, frequency nadir can reach unacceptable values due to excessive power excursions. To correct these frequency deviations, a load-shedding scheme is implemented in the power system, as shown in Table 1.

Table 1. Load-shedding scheme characteristics in El Hierro isolated power system.

\begin{tabular}{ccccc}
\hline UFLS Stages & Frequency Threshold $(\mathbf{H z})$ & RoCoF Threshold $\mathbf{( m H z} / \mathbf{s})$ & Delay $(\mathbf{s})$ & Load Shedding Percentage $(\%)$ \\
\hline 1 & 48.5 & 800 & 0.1 & 12.5 \\
2 & 48.2 & 800 & 0.2 & 12.5 \\
3 & 47.8 & 800 & 0.4 & 12.5 \\
4 & 47.5 & 800 & 0.6 & 12.5 \\
\hline
\end{tabular}

\subsection{Generation of $100 \%$ Renewable Scenarios}

Following the methodology presented in the previous section, data from El Hierro power system have been collected, in particular wind power production and demand during 2018. Wind power data have been divided into six different intervals and system electric demand in four ranges. The distribution of these ranges during 2018 are represented in Figure 5.

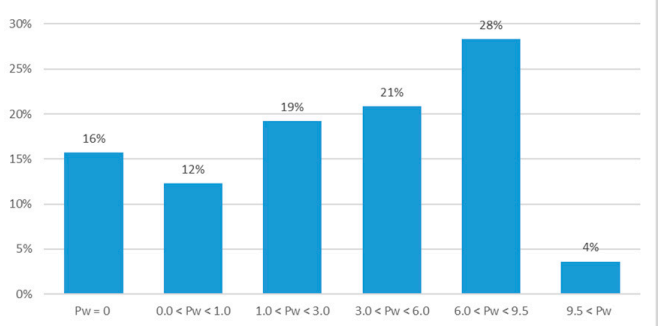

(a)

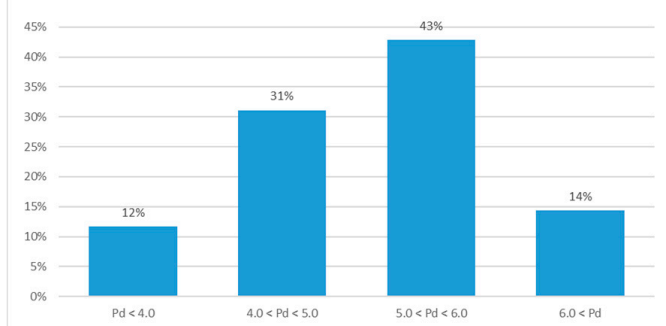

(b)

Figure 5. 2018 El Hierro power system distributions of (a) wind power and (b) power demand.

The combination of both demand and wind power ranges leads to the definition of 22 different schedules-see Table 2. Obviously, the schedules related to no wind power ( $16 \%$ in Figure 5 a) have not been included. Some possible combinations have not been included either because they have not been registered during 2018. In Table 2, there are some schedules with the same demand and wind power range, but they correspond to different cases of power demand that are higher or lower than the wind power. The resulting net demand is covered by Pelton units and pumps following the rules listed in the section above. The pump station is particularly necessary when the wind power is higher than the demand (negative net demand). Each schedule is associated with a percentage of occurrence according to 2018 data. The sum of all the percentages is $84.22 \%$.

According to Table 2, there are 10 different initial wind power values. Therefore, it is necessary to generate the same number of wind speed signals, as directed in Section 4.2, with the parameters indicated in Table A1 (Appendix A). The ten generated wind speed signals are plotted in Figure A1. (Appendix A). In this figure, it can be noted that the variability of wind signals is related to the initial wind speed. 
Table 2. Twenty-two generated schedules and its associated percentage of occurrence during 2018.

\begin{tabular}{|c|c|c|c|c|c|c|c|c|}
\hline Schedule & $\begin{array}{l}\text { Power Demand } \\
\text { Range (MW) }\end{array}$ & $\begin{array}{l}\text { Wind Power } \\
\text { Range (MW) }\end{array}$ & $\begin{array}{c}\text { Percentage of } \\
\text { Occurrence (2018) \% }\end{array}$ & $\begin{array}{l}\text { Power Demand } \\
\text { (MW) }\end{array}$ & $\begin{array}{l}\text { Wind Power } \\
\text { (MW) }\end{array}$ & $\begin{array}{l}\text { Pelton Units } \\
\text { (MW) }\end{array}$ & FSPs (MW) & VSPs (MW) \\
\hline 2 & $4.0<\mathrm{Pd}<5.0$ & $0.0<\mathrm{Pe}<1.0$ & 4.37 & 4.50 & $5 \times 0.15$ & $3 \times 1.25$ & 0 & 0 \\
\hline 3 & $5.0<\mathrm{Pd}<6.0$ & $0.0<\mathrm{Pe}<1.0$ & 4.25 & 5.50 & $5 \times 0.15$ & $3 \times 1.58$ & 0 & 0 \\
\hline 5 & $\mathrm{Pd}<4.0$ & $1.0<\mathrm{Pe}<3.0$ & 2.69 & 3.75 & $5 \times 0.40$ & $3 \times 0.92$ & 0 & $1 \times 1$ \\
\hline 6 & $4.0<\mathrm{Pd}<5.0$ & $1.0<\mathrm{Pe}<3.0$ & 6.88 & 4.50 & $5 \times 0.40$ & $3 \times 0.83$ & 0 & 0 \\
\hline 7 & $5.0<\mathrm{Pd}<6.0$ & $1.0<\mathrm{Pe}<3.0$ & 8.31 & 5.50 & $5 \times 0.40$ & $3 \times 1.17$ & 0 & 0 \\
\hline 10 & $\mathrm{Pd}<4.0$ & $3.0<\mathrm{Pe}<6.0$ & 1.95 & 3.75 & $5 \times 0.90$ & $3 \times 1.05$ & $2 \times 0.50$ & $2 \times 1.45$ \\
\hline 11 & $4.0<\mathrm{Pd}<5.0$ & $3.0<\mathrm{Pe}<6.0$ & 3.98 & 4.50 & $5 \times 0.70$ & $3 \times 1.03$ & 0 & $2 \times 1.05$ \\
\hline 12 & $4.0<\mathrm{Pd}<5.0$ & $3.0<\mathrm{Pe}<6.0$ & 3.14 & 4.50 & $5 \times 1.00$ & $3 \times 1.20$ & $3 \times 0.50$ & $2 \times 1.30$ \\
\hline 13 & $5.0<\mathrm{Pd}<6.0$ & $3.0<\mathrm{Pe}<6.0$ & 7.62 & 5.50 & $5 \times 0.90$ & $3 \times 1.07$ & 0 & $2 \times 1.10$ \\
\hline 14 & $5.0<\mathrm{Pd}<6.0$ & $3.0<\mathrm{Pe}<6.0$ & 1.41 & 5.50 & $5 \times 1.14$ & $3 \times 1.23$ & $2 \times 0.50$ & $2 \times 1.45$ \\
\hline 15 & $6.0<\mathrm{Pd}$ & $3.0<\mathrm{Pe}<6.0$ & 2.12 & 6.25 & $5 \times 0.90$ & $3 \times 1.05$ & 0 & $1 \times 1.40$ \\
\hline 16 & $\mathrm{Pd}<4.0$ & $6.0<\mathrm{Pe}<9.5$ & 3.25 & 3.75 & $5 \times 1.50$ & $3 \times 0.75$ & $6 \times 0.50$ & $2 \times 1.50$ \\
\hline 21 & $5.0<\mathrm{Pd}<6.0$ & $9.5<\mathrm{Pe}<11.5$ & 1.82 & 5.80 & $5 \times 1.94$ & $3 \times 1.33$ & $6 \times 0.50$ & $2 \times 1.50$ \\
\hline 22 & $6.0<\mathrm{Pd}$ & $9.5<\mathrm{Pe}<11.5$ & 1.72 & 6.25 & $5 \times 2.00$ & $3 \times 0.70$ & $6 \times 0.50$ & $2 \times 1.50$ \\
\hline \multicolumn{3}{|c|}{ Total percentage of occurrence during 2018} & $84.22 \%$ & & & & & \\
\hline
\end{tabular}

Four different control strategies are implemented in VSWTs:

- No control action (base case).

- Inertial response.

- $\quad$ Primary regulation (R1).

- $\quad$ Inertial response and primary regulation acting together.

The VSWTs' regulation action, when they are asked to provide primary regulation, depends on the regulation reserve. In this paper, two different reserves are considered: $5 \%$ and $10 \%$ of the initial wind power $(r=0.05$ and $r=0.10)$.

Finally, as described in Section 3.4, primary regulation is coordinated by "the wind farm control", which sends the control signal to the VSWTs. This process involves a delay that may worsen the regulation results. In [20], this delay is quantified as $500 \mathrm{~ms}$ for VSWTs of type 3 and $1500 \mathrm{~ms}$ for VSWTs of type 4. In this research work, even though the VSWTs in El Hierro are type 4, three different cases are compared: no delay, 500 ms delay and 1500 ms delay.

In next subsections, the results of varying schedule, control strategy, primary reserve and R1 time delay are presented.

\subsection{Variable Wind Speed Simulations Results}

According to the methodology described in previous sections, a total number of 22 schedules associated to wind speed signal have been obtained. The four analyzed VSWTs control strategies, the two different wind power reserves and the three primary regulation delays have been simulated.

For that reason, in order to clarify the obtained results, both the average values of the 22 schedules and their $95 \%$ confidence intervals of different quality parameters are listed in the following tables. The 95\% confidence intervals have been obtained according to expression (16), assuming that all values fit a Student's t-Distribution, as the sample size is below thirty [44].

$$
\bar{x} \pm t(\alpha, n) S_{m}
$$

Table 3 lists both the minimum and maximum boundaries of frequency (Nadir and Max F), the frequency Mean Square Error (MSE) and the minimum RoCoF value (i.e., the worst value). In general terms, it is verified that the response of the system, according to the different VSWT control strategies, is predictable. It is observed, analyzing the results in detail, that the power system response is better in the case in which the inertial contribution of the VSWTs acts than in the case in which 
the VSWTs provide primary frequency regulation, reducing both frequency extreme values and MSE. Likewise, the worst value of RoCoF is further reduced because of the inertial regulation. The joint action of both inertial contribution and primary regulation improves the response of the system, but not significantly. Analogously, the increase in the primary regulation power reserve does not substantially improve the quality of the frequency either. VSWTs primary regulation reserve implies that both Pelton units and VSWTs initially supplied a different power value than if VSWTs provided inertial contribution. According to [29], the quality of the frequency would improve if the controllers' gains of Pelton units and VSWTs changed to the proper ones associated to the real operating point. Moreover, including VSWTs primary control delay influences negatively the frequency quality parameters, highlighting the importance of its inclusion in the model.

Table 3. Average values of the twenty-two schedules of frequency parameters considering proposed VSWTs contributions, reserves and delays.

\begin{tabular}{|c|c|c|c|c|c|c|}
\hline \multirow{3}{*}{ VSWT Contribution } & \multirow{3}{*}{ VSWT Reserve } & \multirow{3}{*}{ VSWT R1 Delay } & \multicolumn{4}{|c|}{ Frequency Parameters } \\
\hline & & & Nadir & Max F & MSE & Min. RoCoF \\
\hline & & & $(\mathrm{Hz})$ & (Hz) & $10^{-5}$ p.u. & $(\mathrm{Hz} / \mathrm{s})$ \\
\hline None & - & - & $48.6292 \pm 0.2116$ & $51.3270 \pm 0.1396$ & $11.1 \pm 2.57$ & $-0.5603 \pm 0.1742$ \\
\hline Inertial & - & - & $48.8521 \pm 0.2079$ & $51.1242 \pm 0.1417$ & $8.40 \pm 1.90$ & $-0.2888 \pm 0.0350$ \\
\hline R1 & $5 \%$ & \multirow{4}{*}{0} & $48.9382 \pm 0.1956$ & $51.0997 \pm 0.1462$ & $7.77 \pm 1.84$ & $-0.3582 \pm 0.0737$ \\
\hline R1 & $10 \%$ & & $48.9689 \pm 0.1924$ & $51.0931 \pm 0.1390$ & $7.67 \pm 1.77$ & $-0.3151 \pm 0.0538$ \\
\hline Inertial and R1 & $5 \%$ & & $49.0448 \pm 0.1895$ & $50.9427 \pm 0.1260$ & $6.30 \pm 1.61$ & $-0.2426 \pm 0.0362$ \\
\hline Inertial and R1 & $10 \%$ & & $49.0754 \pm 0.1866$ & $50.9550 \pm 0.1312$ & $6.12 \pm 1.52$ & $-0.2409 \pm 0.0370$ \\
\hline $\mathrm{R} 1$ & $5 \%$ & \multirow{4}{*}{$500 \mathrm{~ms}$} & $48.9360 \pm 0.1951$ & $51.1047 \pm 0.1489$ & $7.62 \pm 1.75$ & $-0.3472 \pm 0.0540$ \\
\hline $\mathrm{R} 1$ & $10 \%$ & & $48.9626 \pm 0.1916$ & $51.0930 \pm 0.1400$ & $7.57 \pm 1.72$ & $-0.3625 \pm 0.0669$ \\
\hline Inertial and R1 & $5 \%$ & & $49.0459 \pm 0.1905$ & $50.9495 \pm 0.1272$ & $6.06 \pm 1.45$ & $-0.2751 \pm 0.0632$ \\
\hline Inertial and R1 & $10 \%$ & & $49.0758 \pm 0.1877$ & $50.9606 \pm 0.1316$ & $5.80 \pm 1.34$ & $-0.2476 \pm 0.0385$ \\
\hline $\mathrm{R} 1$ & $5 \%$ & \multirow{4}{*}{$1500 \mathrm{~ms}$} & $48.8663 \pm 0.1872$ & $51.1544 \pm 0.1523$ & $8.05 \pm 1.73$ & $-0.3933 \pm 0.0583$ \\
\hline $\mathrm{R} 1$ & $10 \%$ & & $48.8880 \pm 0.1828$ & $51.1531 \pm 0.1472$ & $7.91 \pm 1.64$ & $-0.4080 \pm 0.0637$ \\
\hline Inertial and R1 & $5 \%$ & & $49.0450 \pm 0.1922$ & $50.9704 \pm 0.1323$ & $6.14 \pm 1.51$ & $-0.3037 \pm 0.0709$ \\
\hline Inertial and R1 & $10 \%$ & & $49.0726 \pm 0.1888$ & $50.9784 \pm 0.1363$ & $5.98 \pm 1.42$ & $-0.2652 \pm 0.0411$ \\
\hline
\end{tabular}

Figure 6, which contains graphical results obtained from schedule number 13 taken as an example, shows the frequency dynamic response assuming the different VSWTs control strategies. As can be seen, the upper and lower values of the frequency improve, approaching the nominal frequency of the system, thanks to the contribution of the VSWTs.

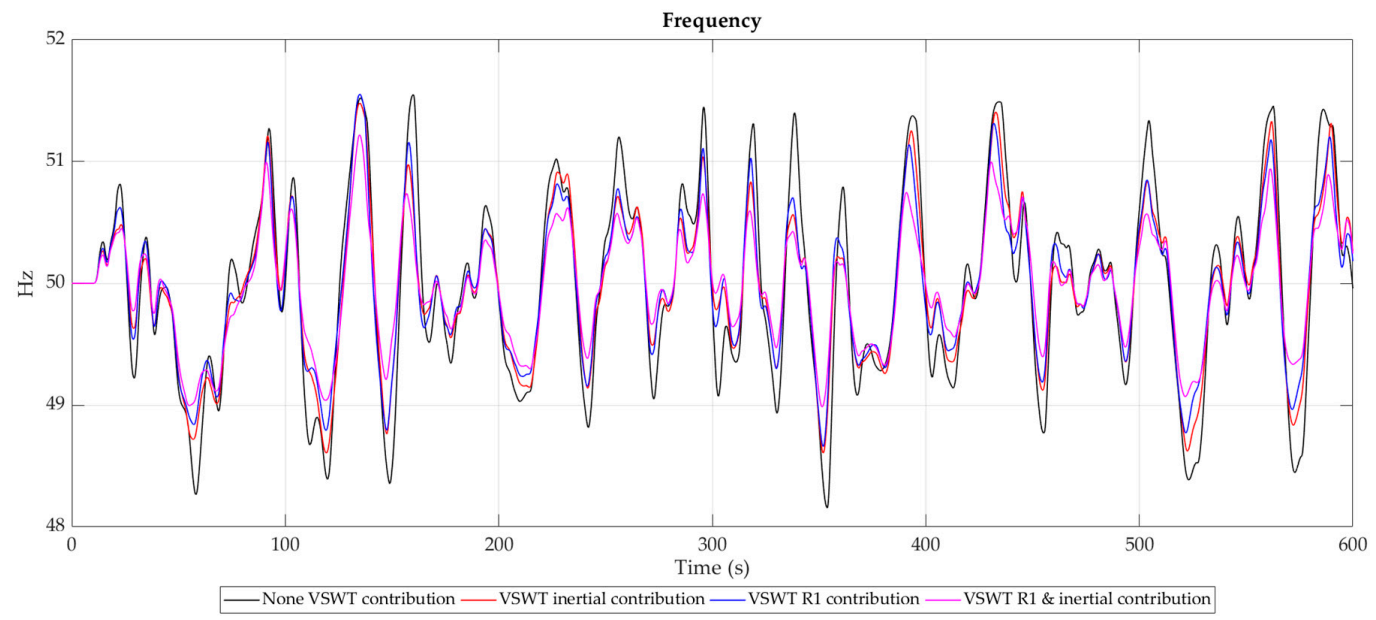

Figure 6. Frequency dynamic response in the cases none VSWT contribution, VSWT inertial contribution, primary frequency regulation (R1) contribution and R1 and inertial contribution (5\% power reserve).

Table 4 lists the average values of the hydraulic parameters: pumped and turbined water volumes and the sum of the wicket gate movements. On the one hand, pumped values do not vary significantly, 
regardless of the type of VSWT control strategy. Note that, according to the criteria described in Section 4.1, the initial power consumed by the pumps has remained constant in each scenario, regardless of the type of contribution of the VSWTs. Therefore, small variations depend on the control effort of the VSPs. However, it is appreciated that the inertial contribution of the VSWTs allows a small saving in pumped volume, acting both individually and together with the primary regulation.

Table 4. Average values of hydraulic parameters considering the proposed VSWT contributions.

\begin{tabular}{|c|c|c|c|c|c|}
\hline \multirow{2}{*}{ VSWT Contribution } & \multirow{2}{*}{ VSWT Reserve } & \multirow{2}{*}{ VSWT R1 Delay } & Pumped Volume & Turbined Volume & $\frac{\int(\Delta z) d t}{t}$ \\
\hline & & & $\left(m^{3}\right)$ & $\left(m^{3}\right)$ & $10^{-4}$ (p.u.) \\
\hline None & - & - & $276.70 \pm 103.01$ & $211.29 \pm 17.66$ & $4.16 \pm 0.554$ \\
\hline Inertial & - & - & $275.42 \pm 103.36$ & $210.63 \pm 17.76$ & $2.42 \pm 0.158$ \\
\hline R1 & $5 \%$ & \multirow{4}{*}{0} & $275.88 \pm 103.55$ & $216.16 \pm 17.68$ & $4.08 \pm 0.525$ \\
\hline R1 & $10 \%$ & & $276.38 \pm 103.76$ & $222.01 \pm 17.99$ & $3.88 \pm 0.302$ \\
\hline Inertial and R1 & $5 \%$ & & $275.25 \pm 103.79$ & $216.98 \pm 17.88$ & $1.73 \pm 0.081$ \\
\hline Inertial and R1 & $10 \%$ & & $275.91 \pm 104.05$ & $222.73 \pm 18.25$ & $1.80 \pm 0.085$ \\
\hline R1 & $5 \%$ & \multirow{4}{*}{$500 \mathrm{~ms}$} & $275.97 \pm 103.57$ & $216.25 \pm 17.68$ & $3.89 \pm 0.029$ \\
\hline R1 & $10 \%$ & & $276.50 \pm 103.79$ & $222.09 \pm 17.99$ & $3.85 \pm 0.399$ \\
\hline Inertial and R1 & $5 \%$ & & $275.35 \pm 103.82$ & $216.98 \pm 17.88$ & $1.77 \pm 0.085$ \\
\hline Inertial and R1 & $10 \%$ & & $276.00 \pm 104.08$ & $222.74 \pm 18.25$ & $1.77 \pm 0.087$ \\
\hline R1 & $5 \%$ & \multirow{4}{*}{$1500 \mathrm{~ms}$} & $276.15 \pm 103.55$ & $216.43 \pm 17.67$ & $2.35 \pm 0.163$ \\
\hline R1 & $10 \%$ & & $276.78 \pm 103.77$ & $222.22 \pm 17.98$ & $2.40 \pm 0.206$ \\
\hline Inertial and R1 & $5 \%$ & & $275.48 \pm 103.85$ & $217.03 \pm 17.91$ & $1.79 \pm 0.092$ \\
\hline Inertial and R1 & $10 \%$ & & $276.11 \pm 104.09$ & $222.79 \pm 18.26$ & $1.86 \pm 0.964$ \\
\hline
\end{tabular}

On the other hand, the turbined volume is affected by the VSWT regulation strategy. As previously indicated, the VSWTs' primary regulation requires maintaining a power regulation reserve, reducing the power they supply. For this reason, Pelton units must compensate for this reduction, increasing their power and, therefore, the turbined water volume. The greater the $\mathrm{R} 1$ regulation reserve, the greater the increase in turbined water volume. Adding inertial response or considering control delay does not affect the water volumes.

The main advantage of VSWTs' contribution to frequency regulation in terms of hydraulic parameters lies in the gate opening movements of the hydroelectric units, measured through the sum of their increments. The largest increases take place when the VSWTs provide inertial and primary regulation together. This reduction is significant, even taking into account the R1 control action delay, and it implies an extension of the remaining lifetime of the turbine components.

Table 5 lists the average values of the VSWT parameters: the total energy supplied by the VSWTs and the sum of blade movements. As expected, there is a decrease in the energy supplied by the VSWTs when they provide R1 due to the need to maintain a regulation power reserve. A wind spill occurs because a non-optimal working point in the power-rotor speed curve of the turbine is achieved. This is also verified in Figure 7, which contains graphical results obtained from schedule number 13 taken as an example. It can be seen how the higher values of wind power obtained when VSWTs do not provide R1 are not reached by the generated power in the cases in which VSWTs provide R1. However, there is also a small increase in the wind energy supplied due to the inertial regulation of the VSWTs. The supplied wind energy is not affected by the R1control action delay.

The variations in the blade position are also collected in the Table 5 through the sum of their increases. The sum of the blade position increments is not greatly affected by the VSWT control strategy. A small increase in these movements is seen in the case where the VSWTs exclusively provide R1, which is reduced if the inertial contribution is added. However, in Figure 8, which contains graphical results obtained from schedule number 13, it can be seen how the blade position reaches values much higher than those reached with any kind of VSWT control strategy. In some moments, differences of more than 5 degrees are reached. This fact is also detectable in the variations in the blade position confidence interval (Table 5), which is drastically reduced because of the inertial contribution. 
Table 5. Average values of VSWT parameters considering the proposed VSWT contributions.

\begin{tabular}{|c|c|c|c|c|}
\hline \multirow{2}{*}{ VSWT Contribution } & \multirow{2}{*}{ VSWT Reserve } & \multirow{2}{*}{ VSWT R1 Delay } & \multirow{2}{*}{$\begin{array}{c}\text { Wind Energy } \\
(\mathrm{kWh})\end{array}$} & \multirow{2}{*}{$\frac{\frac{\int(\Delta \beta) d t}{t}}{10^{-2} \text { (p.u.) }}$} \\
\hline & & & & \\
\hline None & - & - & $626.49 \pm 171.48$ & $3.33 \pm 0.680$ \\
\hline Inertial & - & - & $630.71 \pm 170.65$ & $3.27 \pm 0.188$ \\
\hline R1 & $5 \%$ & \multirow{4}{*}{0} & $613.50 \pm 165.36$ & $3.95 \pm 0.769$ \\
\hline $\mathrm{R} 1$ & $10 \%$ & & $595.54 \pm 159.96$ & $5.39 \pm 0.243$ \\
\hline Inertial and R1 & $5 \%$ & & $612.99 \pm 164.22$ & $2.73 \pm 0.166$ \\
\hline Inertial and R1 & $10 \%$ & & $595.66 \pm 159.05$ & $2.91 \pm 0.136$ \\
\hline R1 & $5 \%$ & \multirow{4}{*}{$500 \mathrm{~ms}$} & $613.13 \pm 165.39$ & $5.51 \pm 0.288$ \\
\hline $\mathrm{R} 1$ & $10 \%$ & & $595.19 \pm 159.95$ & $5.43 \pm 0.348$ \\
\hline Inertial and R1 & $5 \%$ & & $612.94 \pm 164.27$ & $2.88 \pm 0.140$ \\
\hline Inertial and R1 & $10 \%$ & & $595.57 \pm 159.09$ & $2.91 \pm 0.173$ \\
\hline R1 & $5 \%$ & \multirow{4}{*}{$1500 \mathrm{~ms}$} & $612.18 \pm 165.46$ & $3.35 \pm 0.224$ \\
\hline $\mathrm{R} 1$ & $10 \%$ & & $594.39 \pm 159.97$ & $3.35 \pm 0.241$ \\
\hline Inertial and R1 & $5 \%$ & & $612.57 \pm 164.31$ & $2.96 \pm 0.111$ \\
\hline Inertial and R1 & $10 \%$ & & $595.13 \pm 159.04$ & $3.12 \pm 0.112$ \\
\hline
\end{tabular}

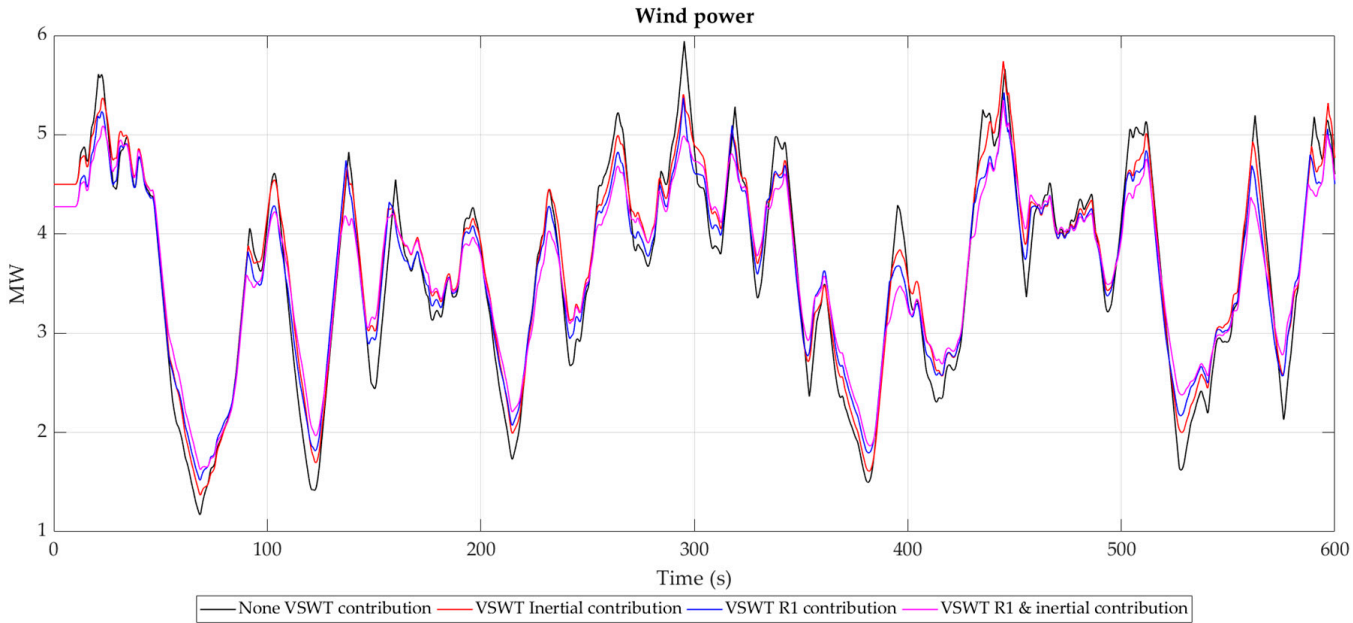

Figure 7. Wind power production in the cases none VSWT contribution, VSWT inertial contribution, $\mathrm{R} 1$ contribution and R1 and inertial contribution (5\% power reserve).

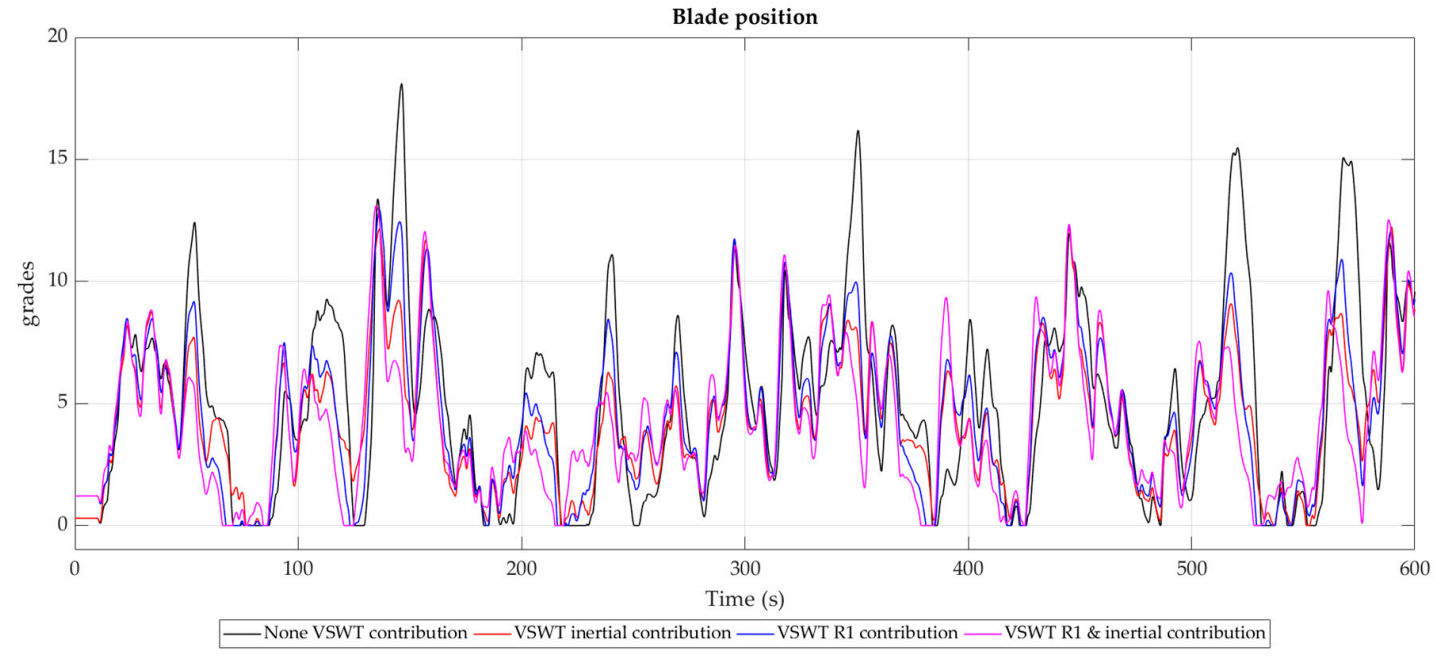

Figure 8. Blade position in the cases none VSWT contribution, VSWT inertial contribution, $\mathrm{R} 1$ contribution and R1 and inertial contribution (5\% power reserve), respectively. 
These wide variations obstruct the blade position adaptation to the needs of the wind turbine due to the limitation in the speed of its movements.

Table 6 collects the influence of the VSWT regulation strategies on the annual supplied wind energy and the hydraulic balance of the hydropower plant (pumped volume of water minus turbined volume of water). These data are extended listing schedule by schedule in Table A3 in Appendix A. The annual values have been calculated as the weighted average with respect to the percentage of occurrence of each generation schedule for the year 2018. It is important to notice the variability of the data contained in the mentioned Table A3 in contrast with the final values of Table 6 . Both the wind energy and hydraulic balance heavily depend on the programmed schedule. For example, in the case of only $10 \%$ R 1 reserve, the wind energy is reduced from $2.13 \%$ in schedule 15 to $8.74 \%$ in schedule 22 with respect to the base case with no VSWT regulation. The same performance can be observed in the case of water balance. For the same control strategy, in schedule 5 the volume of pumped water is improved by $23 \%$, and in schedule 13 it is reduced by $39.4 \%$. This fact highlights the use of multiple programmed schedules proposed in the methodology of this paper in order to obtain a wide vision of the matter.

Table 6. Aggregated comparison of the hydraulic balance (difference between pumped and turbined volume) and wind energy produced between none VSWT contribution and the proposed VSWT regulation strategy.

\begin{tabular}{ccccccc}
\hline & & Annual Value Assuming \\
& No VSWT Regulation & & \multicolumn{4}{c}{$\begin{array}{c}\text { Variation Respect None VSWT Contribution Considering Different } \\
\text { VSWTs Regulation Strategy }\end{array}$} \\
\cline { 3 - 7 } & & Inertial & $\mathbf{R 1 ~ ( r = 5 \% )}$ & $\mathbf{R 1}(\mathbf{r}=\mathbf{1 0} \%)$ & $\begin{array}{c}\text { Inertial and } \\
\mathbf{R 1}(\mathbf{r}=\mathbf{5} \%)\end{array}$ & $\begin{array}{c}\text { Inertial and } \\
\mathbf{R 1}(\mathbf{r}=\mathbf{1 0} \%)\end{array}$ \\
\hline $\begin{array}{c}\text { Hydraulic } \\
\text { balance }\end{array}$ & $3.69 \mathrm{hm}^{3}$ & $-0.76 \%$ & $-6.75 \%$ & $-12.53 \%$ & $-8.76 \%$ & $-14.18 \%$ \\
\hline Wind energy & $28.75 \mathrm{GWh}$ & $0.51 \%$ & $-2.05 \%$ & $-4.57 \%$ & $-2.20 \%$ & $-4.60 \%$ \\
\hline
\end{tabular}

Due to the contribution of the VSWTs to primary frequency regulation, it is verified that there is a decrease in the annual hydraulic balance-that is, a reduction in the pumped water volume and an increase in the turbined volume. On the one hand, the reduction in the pumped volume is due to the decrease in the wind energy supplied - that is, the power consumed by the pumps decreases due to a deficit in wind energy production. On the other hand, this reduction in the wind energy-supplied due to the contribution of VSWTs to frequency regulation causes the energy produced by the Pelton units to increase, implying an increase in the turbinated water volume. In the case of inertial contribution, this effect is limited.

Regarding the annual wind energy supplied by the wind farm, a clear reduction is seen when the VSWTs provide R1 due to the requirement to maintain a power reserve and be operating below their optimum production curve. This means that the improvement in the quality of the frequency takes place at the cost of a reduction in the energy efficiency of the system. Undoubtedly, this annual energy loss is greater the larger the power regulation reserve maintained. However, the proportion of wind energy reduction is much lower than the wind power reserve. This fact has already been verified in [25]. If inertial regulation is added to the VSWT R1 contribution, the energy loss increases, reducing the energy efficiency. Conversely, when the VSWTs only provides inertial regulation, a small increase in wind power produced annually is seen.

However, it should be noted that for all generation schedules and for all regulation strategies, all the controllers' gains have been kept constant (see Table A2 in Appendix A). Given the authors' experience in previous studies, it is expected that better results may be obtained with specific controller gains tuned for each generation schedule and each regulation strategy. 


\subsection{Outage of the Generation Unit with the Highest Assigned Power}

The outage of the generation unit with the highest assigned power, "biggest operating unit", has been simulated for each representative schedule assuming the different VSWTs control strategies with the analyzed R1 hypotheses-i.e., different values both of regulation reserves and control action delays. The average values and their $95 \%$ confidence intervals of three variables have been measured: (i) nadir; (ii) RoCoF, measured as the average during the first 150 and 1000 ms after the power disturbance; and (iii) the load-shedding amount when the "biggest operating unit" outage takes place. These measurements are listed in Table 7.

Table 7. Average of nadir, Rate of Change of Frequency (RoCoF) and load-shedding amount and (1) number of schedules in which at least one load-shedding step is needed, considering different VSWT contributions when the biggest operating unit outage takes place.

\begin{tabular}{cccccccc}
\hline VSWT Contribution & VSWT Reserve & R1 Delay & Nadir $\mathbf{( H z )}$ & RoCoF 150 ms (Hz/s) & RoCoF 1000 ms (Hz/s) & Load-Shedding & $\mathbf{( 1 )}$ \\
\hline None & - & - & $48.6618 \pm 0.1709$ & $-1.5731 \pm 0.1735$ & $-0.7867 \pm 0.1136$ & $0.636 \pm 0.342$ & 10 \\
\hline Inertial & - & - & $48.8614 \pm 0.1718$ & $-1.5527 \pm 0.1722$ & $-0.7013 \pm 0.1194$ & $0.364 \pm 0.285$ & 6 \\
\hline R1 & $5 \%$ & & $48.8078 \pm 0.1776$ & $-1.5872 \pm 0.1753$ & $-0.7256 \pm 0.1144$ & $0.455 \pm 0.291$ & 8 \\
R1 & $10 \%$ & 0 & $48.7831 \pm 0.1816$ & $-1.6180 \pm 0.1851$ & $-0.7446 \pm 0.1178$ & $0.500 \pm 0.291$ & 9 \\
Inertial and R1 & $5 \%$ & & $48.8751 \pm 0.1752$ & $-1.5872 \pm 0.1753$ & $-0.7143 \pm 0.1164$ & $0.364 \pm 0.285$ & 6 \\
Inertial and R1 & $10 \%$ & & $48.8451 \pm 0.1772$ & $-1.6180 \pm 0.1851$ & $-0.7341 \pm 0.1192$ & $0.364 \pm 0.285$ & 6 \\
\hline R1 & $5 \%$ & & $48.7574 \pm 0.1780$ & $-1.6083 \pm 0.1767$ & $-0.7704 \pm 0.1145$ & $0.455 \pm 0.291$ \\
R1 & $10 \%$ & \multirow{2}{*}{$\mathrm{ms}$} & $48.7302 \pm 0.1822$ & $-1.6391 \pm 0.1868$ & $-0.7870 \pm 0.1159$ & $0.545 \pm 0.291$ & 10 \\
Inertial and R1 & $5 \%$ & & $48.8751 \pm 0.1752$ & $-1.5872 \pm 0.1753$ & $-0.7143 \pm 0.1164$ & $0.364 \pm 0.285$ & 6 \\
Inertial and R1 & $10 \%$ & & $48.8451 \pm 0.1772$ & $-1.6180 \pm 0.1851$ & $-0.7341 \pm 0.1192$ & $0.364 \pm 0.285$ & 6 \\
\hline R1 & $5 \%$ & & $48.6582 \pm 0.1760$ & $-1.6083 \pm 0.1767$ & $-0.8038 \pm 0.1140$ & $0.636 \pm 0.342$ & 10 \\
R1 & $10 \%$ & \multirow{2}{*}{$1500 \mathrm{~ms}$} & $48.6363 \pm 0.1801$ & $-1.6391 \pm 0.1868$ & $-0.8248 \pm 0.1186$ & $0.727 \pm 0.332$ & 12 \\
Inertial and R1 & $5 \%$ & & $48.8624 \pm 0.1734$ & $-1.5872 \pm 0.1753$ & $-0.7152 \pm 0.1160$ & $0.364 \pm 0.285$ & 6 \\
Inertial and R1 & $10 \%$ & & $48.8370 \pm 0.1764$ & $-1.6180 \pm 0.1851$ & $-0.7345 \pm 0.1190$ & $0.364 \pm 0.285$ & 6 \\
\hline
\end{tabular}

As observed, the inertial contribution of the VSWTs improves the nadir value of the frequency acting individually or jointly with R1. In fact, activating the inertial contribution of the VSWTs improves the response provided by the VSWTs R1 contribution, regardless of the power reserve.

The value of the nadir also depends on the characteristics of the R1 contribution - that is, the wind regulation reserve-as well as the delay in the control action. Contrary to what might be expected, a higher regulatory reserve does not improve the value of the nadir. Figures 9 and 10, which contain graphical results obtained from schedule number 13, explain this fact. It is observed that the injected power signal due to the R1 contribution is limited by the maximum rate of variation in wind power, regardless of the regulation reserve. Therefore, since the frequency disturbance occurs, the contribution of VSWTs follows a straight path. Thus, the power increase provided by the VSWTs before the nadir takes place is the same, independently of the regulation reserve. Moreover, the injected power is less the greater the regulation reserve (note that the initial wind power is less and the increase is the same). This phenomenon is due to the limit on the variation rate of wind power and cannot be avoided, even if appropriate R1 controller gains are used.

In this sense, the value of the nadir varies depending on the wind regulation reserve because the operating point of the Pelton units is modified.

Regarding the RoCoF values collected in Table 7, it is verified that the best ones are reached when the VSWTs provide inertial regulation. It is also observed that the RoCoF values slightly worsen as the regulation reserve increases. Since the power injected by VSWTs is limited by the maximum variation rate of wind power, and this is saturated in any case, the only parameter that varies between the R1 control strategies is the initial power of the VSWTs and, consequently, the initial power of the Pelton units. This fact is confirmed in Figure 9. Furthermore, it is observed that the value of the RoCoF measured in the first $150 \mathrm{~ms}$ when the VSWTs provides only R1 without considering delay and the value measured if the VSWTs jointly provide inertial regulation and R1 are identical $(-1.5872 \mathrm{~Hz} / \mathrm{s}$ and $-1.6180 \mathrm{~Hz} / \mathrm{s}$ if there is $5 \%$ or $10 \%$ of regulation reserve, respectively). Again, this is because the contribution is limited by the maximum rate of variation in wind power. 

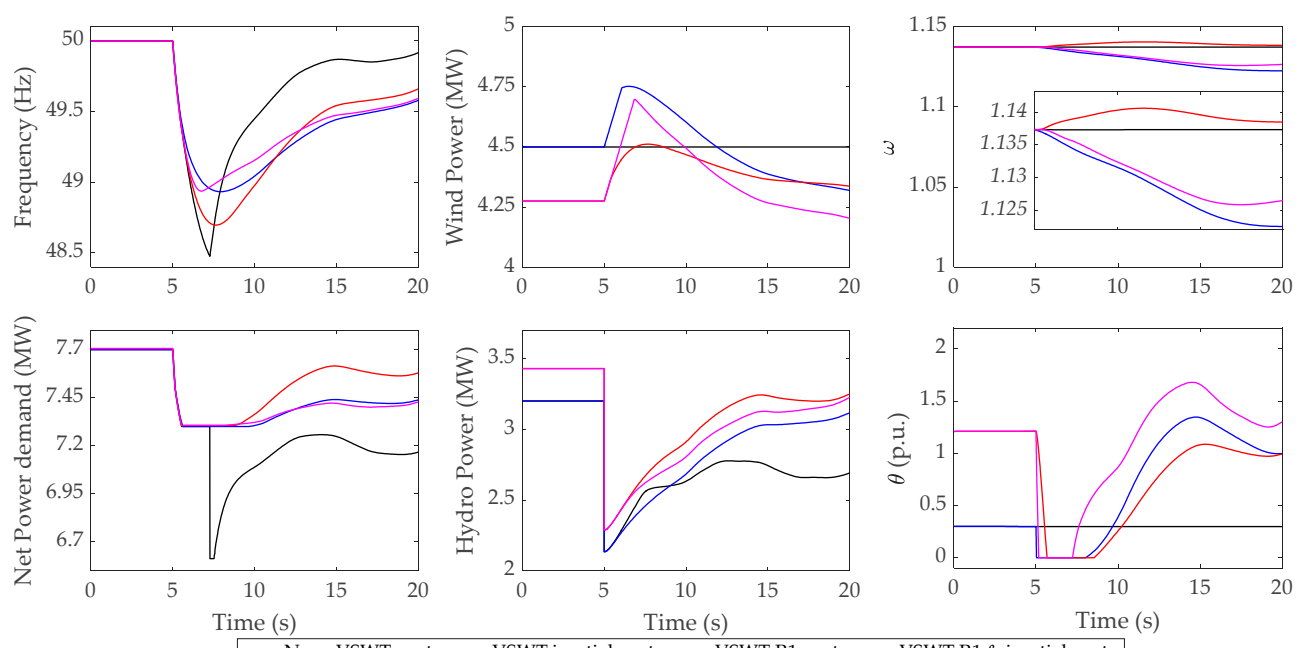

Figure 9. Dynamic system response considering different VSWT contributions when the "biggest operating unit" outage takes place.
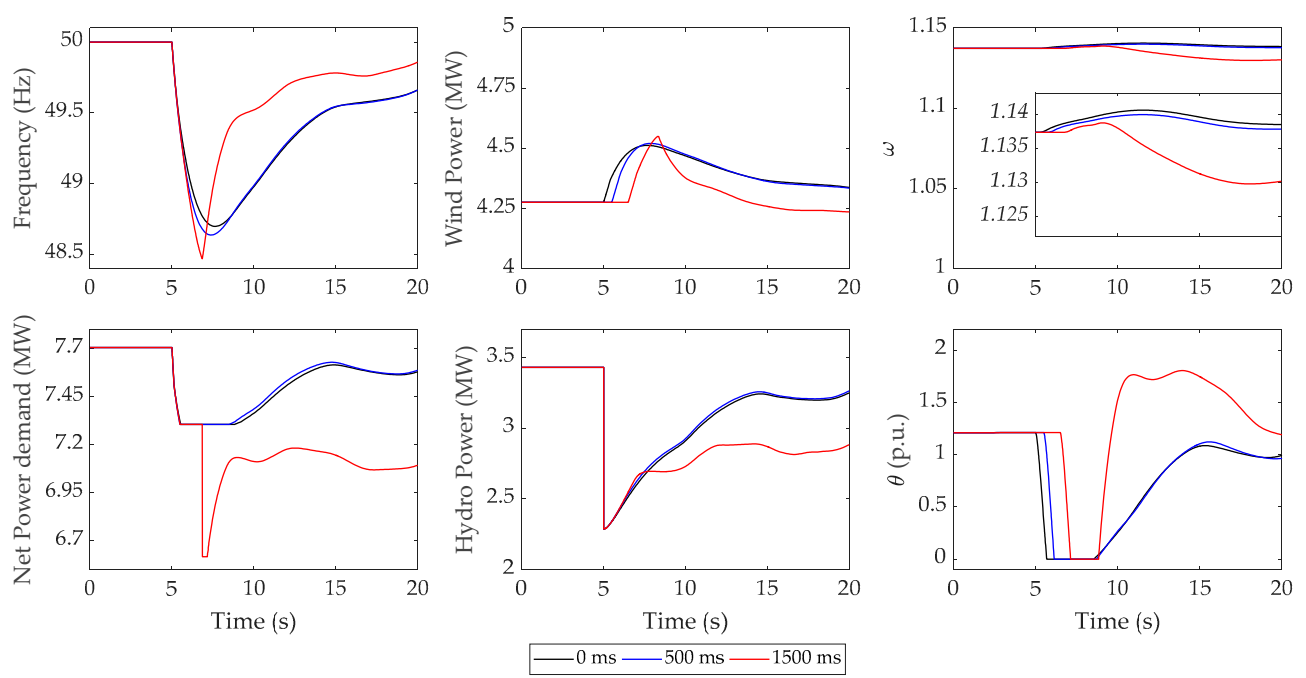

Figure 10. Dynamic system response considering the R1 VSWT contribution, assuming different R1 action delays when the "biggest operating unit" outage takes place.

Different R1 control action delays also affect the RoCoF values. If the control action of the R1 contribution acts without any delay, it influences the RoCoF value measured in the first $150 \mathrm{~ms}$; this value is better than the one measured during the same time if the control action is delayed by either 500 or $1500 \mathrm{~ms}$. For example, assuming that the VSWTs provide R1 with a 5\% wind reserve and zero delay, the average value of the RoCoF the first $150 \mathrm{~ms}$ is $-1.5872 \mathrm{~Hz} / \mathrm{s}$, while, including a delay of 500 or $1500 \mathrm{~ms}$, the RoCoF reaches $-1.6083 \mathrm{~Hz} / \mathrm{s}$ in both cases. Obviously, if the RoCoF is measured during the first $1000 \mathrm{~ms}$ after the frequency disturbance, there is a difference between the value obtained with a delay of $500 \mathrm{~ms}$ and that obtained with a delay of $1500 \mathrm{~ms}$.

The activation of load shedding steps is also reduced because of the contribution of the VSWTs to frequency regulation, except in only one case (contribution $\mathrm{R} 1$ with $10 \%$ of regulation reserve and a delay of $1500 \mathrm{~ms}$ ) in which the average value increases. Furthermore, the number of schedules in which the activation of load shedding steps is necessary is reduced. This reduction is maximum when the VSWTs provide inertial regulation, either exclusively or jointly with R1 contribution.

As observed in Figure 10, load shedding cannot be avoided (note that the RoCoF reaches values higher than $800 \mathrm{mHz} / \mathrm{s}$, which is the activation condition of the shedding scheme according to Table 1) 
if the control action is received with a delay of $1500 \mathrm{~ms}$ in schedule 13 , obtaining a similar response to the case in which the VSWTs do not provide frequency regulation in Figure 9.

\section{Conclusions}

In this paper, a methodology to assess the main benefits and disadvantages of introducing different control strategies in VSWTs in an exclusively renewable isolated power system has been proposed. In addition to control strategies, several regulation reserves and time delays in R1 control action have been considered. To achieve this objective, a mathematical model including exclusively renewable technologies has been described. Realistic system events that involve frequency deviations such as fluctuation of the wind speed and the outage of the generation unit with the highest assigned power have been simulated, assuming representative generation schedules according to the observed system demand and wind power generation. This methodology has been applied to the El Hierro isolated power system.

As a general overview, it can be stated that the results obtained from all the schedules are different enough to justify their consideration. Moreover, relating each programming schedule to the recorded data for a specified time period, such as a year, makes it possible to obtain interesting annual indices for comparing VSWTs control strategies in terms of energy or efficiency. The consideration of two types of event (variable wind speed signal and unit outage) also provides valuable and supplementary information. With regard to the introduction of the time delays in the R1 VSWT control, simulation results show that this delay has a real and direct influence on the system frequency response.

With respect to the specific results obtained in the El Hierro power system, its dynamic response is observed to be better in the case in which the inertial contribution of the VSWTs acts than in the case in which the VSWTs provide primary frequency regulation, reducing both the frequency extreme values and the MSE. The increase in the R1 power reserve does not substantially improve the quality of the frequency. However, including the VSWT primary control delay influences negatively the frequency quality parameters, highlighting the importance of its inclusion in the model. Regarding the pumped and turbined flow, the pumped values do not vary significantly regardless of the type of VSWT contribution, but the turbined values are sensitive to the R1 power reserve because the Pelton units must supply the wind power reduction associated with the power reserve. In addition, due to this power reserve, there is a decrease in the energy supplied by the VSWTs. The main advantage of the VSWTs' contribution to primary frequency regulation lies in the gate opening movements of hydroelectric units, which implies an extension of the remaining lifetime of the turbine components.

The inertial contribution of the VSWTs improves the nadir value of the frequency, acting individually or jointly with the R1 VSWT contribution when the outage of the generation unit with the highest assigned power is simulated. The nadir value depends on the characteristics of the R1 contribution - that is, the wind regulation reserve-as well as the delay in the control action. Contrary to what might be expected, a higher regulatory reserve does not improve the value of the nadir. It is observed that the injected power signal due to the R1 contribution is limited by the maximum rate of variation in wind power, regardless of the regulation reserve. Furthermore, different R1 control action delays also affect both the nadir and RoCoF values. The activation of load shedding steps is also reduced thanks to the contribution of the VSWTs to frequency regulation. The number of schedules in which the activation of load shedding steps is necessary is reduced, being maximum when the VSWTs provide inertial regulation either exclusively or jointly with R1 contribution.

Finally, from annual aggregated values it can be affirmed that introducing VSWT control strategies implies a reduction in the efficiency of the hydraulic cycle. The reduction in the annual pumped volume of water ranges from $0.76 \%$ (inertial control) to $14.18 \%$ (inertial and R1 10\%). Nevertheless, the inertial control strategy implies an improvement of $0.51 \%$ in the annual wind energy, while the inertial and R1 10\% control strategy implies a reduction of $4.60 \%$ in the annual wind energy. In this sense, the improvement in the quality of the frequency owing to R1 control takes place at the cost of a reduction in the energy efficiency of the system. 
Author Contributions: The authors have contributed to the completion of this paper according to the following list of tasks: conceptualization, J.I.P.-D.; formal analysis, G.M.-L. and J.I.S.; funding acquisition, J.I.P.-D.; investigation, G.M.-L. and J.I.S.; methodology, G.M.-L. and J.I.S.; resources, G.M.-L. and J.I.S.; software, G.M.-L.; supervision, J.I.P.-D.; validation, G.M.-L. and J.I.S.; writing—original draft, G.M.-L., J.I.S., S.M. and D.O.; writing-review and editing, G.M.-L., J.I.S. and S.M. All authors have read and agreed to the published version of the manuscript.

Funding: This research was funded by MINISTERIO DE ECONOMÍA Y COMPETITIVIDAD, under the project "Value of pumped-hydro energy storage in isolated power systems with high wind power penetration" of the National Plan for Scientific and Technical Research and Innovation 2013-2016, grant number ENE2016-77951-R.

Conflicts of Interest: The authors declare no conflict of interest.

\section{Nomenclature}

$\bar{x}$

$A_{i} \quad[\mathrm{~m} / \mathrm{s}]$

$D_{\text {net }} \quad$ [p.u.]

$f \quad[\mathrm{~Hz}]$

$f_{\text {ref }} \quad$ [1 p.u.]

$K_{\text {diner }}$

$K_{d, v s p}$

$K_{f}$

$K_{i, h y d}$

$K_{i, R 1}$

$K_{i, v s p}$

$K_{i \omega}$

$K_{p, h y d}$

$K_{p, \text { iner }}$

$K_{p, R 1}$

$K_{p, v s p}$

$K_{p \omega}$

$K_{u}$

$K_{u, h y d}$

$K_{u, v s p}$

L

$N_{\text {vsp }, m} \quad$ [r.p.m.]

$p_{d} \quad$ [p.u.]

$p_{f s p} \quad$ [p.u.]

$P_{f s p, k} \quad$ [MW]

phyd [p.u.]

$P_{\text {hyd }, j}$ [MW]

$p_{\text {hyd }, j}$ [p.u.]

$p_{\text {hyd }, j}{ }^{0} \quad$ [p.u.]

$p_{\text {vsp }} \quad$ [p.u.]

$P_{v s p, m} \quad[\mathrm{MW}]$

$p_{\text {vsp }, m^{0}} \quad$ [p.u.]

$\begin{array}{lll}p_{w} & \text { [p.u.] }\end{array}$

$P_{w, n} \quad[\mathrm{MW}]$

$p_{w, n} \quad$ [p.u.]

$P_{w, n}{ }^{0} \quad$ [MW]

$p_{w, n}{ }^{0} \quad$ [p.u.]

$r \quad$ [p.u.]

$S_{m}$

$S_{S S}$

$s_{w} \quad[\mathrm{~m} / \mathrm{s}]$

$s_{w m l} \quad[\mathrm{~m} / \mathrm{s}]$

$s_{w t} \quad[\mathrm{~m} / \mathrm{s}]$

$t(\alpha, n)$

$T_{m, h y d}(t) \quad[\mathrm{s}]$

$T_{\text {sml }} \quad$ [s] average value of a generic variable

amplitude of sinusoidal expression of Van der Hoven's model

system damping

system frequency

reference system frequency

derivative gain of VSWTs inertial control loop

derivative gain of VSPs control loop

$\mathrm{K}$-factor in the control area

integral gain of hydro units control loop

integral gain of VSWT R1 control loop

integral gain of VSPs control loop

integral gain of VSWTs speed control loop

proportional gain of hydro units control loop

proportional gain of VSWTs inertial control loop

proportional gain of VSWTs R1 control loop

proportional gain of VSPs control loop

proportional gain of VSWTs speed control loop

sum of Hydro units and VSPs participation factor

hydro units participation factor

VSPs participation factor

wind farm length scale

$\mathrm{m}$ VSP rotational speed

power demanded

power consumed by FSPs

power consumed by the $\mathrm{k}$ FSP

power supplied by the hydro units

power supplied by the $j$ hydro unit

power supplied by the $\mathrm{j}$ hydro unit

initial power supplied by the $\mathrm{j}$ hydro unit

power consumed by the VSPs

power consumed by the $\mathrm{m}$ VSP

initial power consumed by the $\mathrm{m}$ VSP

power supplied by the wind farms

power supplied by the $n$ VSWT

power supplied by the $\mathrm{n}$ VSWT

initial power supplied by the $\mathrm{n}$ VSWT

initial power supplied by the $\mathrm{n}$ VSWT

fraction of wind power reserve

Standard deviation of results distribution

power spectral density of Van der Hoven's model

wind speed

medium- and long-term component of wind speed

turbulence component of wind speed

$\mathrm{t}$ distribution value for a $(1-\alpha)$ confidence interval and $\mathrm{n}$ elements

hydraulic unit mechanical starting time

Sample period of wind speed medium- and long-term component 


$\begin{array}{lll}z & \text { [p.u.] } & \text { hydro unit wicket gate position } \\ \beta & \text { [ } & \text { VSWTs blade pitch angle } \\ \Delta p_{\text {hyd }} \text { ref } & \text { [p.u.] } & \text { power reference signal provided by AGC to hydro units } \\ \Delta p_{\text {iner }} & \text { [p.u.] } & \text { power reference provided by VSWTs inertial control loop } \\ \Delta p_{\text {prim }, n} & \text { [p.u.] } & \text { power reference provided by VSWTs R1 control loop } \\ \Delta p_{v s p}{ }^{\text {ref }} & \text { [p.u.] } & \text { power reference signal provided by AGC to pump station } \\ \Delta p_{\omega} & \text { [p.u.] } & \begin{array}{l}\text { power reference provided by VSWTs speed control loop } \\ \text { regulation effort }\end{array} \\ \Delta R R & \text { [p.u.] } & \begin{array}{l}\text { wind speed turbulence intensity } \\ \sigma\end{array} \\ \sigma_{H} & \text { [p.u.] } & \text { hydro units speed droop } \\ \sigma_{P} & \text { [p.u.] } & \text { VSPs speed droop } \\ \sigma_{w} & \text { [p.u.] } & \text { VSWTs speed droop } \\ \omega & \text { [p.u.] } & \text { VSWT rotational rotor speed } \\ \omega_{\text {ref }} & \text { [p.u.] } & \text { reference VSWT rotational rotor speed }\end{array}$

\section{Appendix A}

Table A1. Parameters used for the generation of wind speed signals.

\begin{tabular}{ccccc}
\hline$T_{\text {sml }}$ & $\boldsymbol{T}_{\text {st }}$ & $\sigma$ & $\boldsymbol{L}$ & $\boldsymbol{k}_{\sigma, \mathrm{s}}$ \\
\hline $180 \mathrm{~s}$ & $1 \mathrm{~s}$ & $0.16\left(0.75 \overline{s_{w}}+3.75\right)$ & $75.3 \mathrm{~m}$ & 0.25
\end{tabular}

Table A2. Controllers' gains.

\begin{tabular}{ccc}
\hline Control Loop & \multicolumn{2}{c}{ Controller Gains } \\
\hline \multirow{2}{*}{ Pelton units governor } & $K_{p, h y d}$ & 2 \\
& $K_{i, h y d}$ & 1 \\
\hline \multirow{2}{*}{ VSWT inertial control } & $K_{p, i n e r}$ & 2 \\
& $K_{d, i n e r}$ & 0.5 \\
\hline \multirow{2}{*}{ VSWT R1 control loop } & $K_{p, R 1}$ & 0.06 \\
& $K_{i, R 1}$ & 0.006 \\
\hline \multirow{2}{*}{ VSWT speed control } & $K_{p \omega}$ & 1 \\
& $K_{i \omega}$ & 0.15 \\
\hline \multirow{2}{*}{ VSP governor } & $K_{p, v s p}$ & 3 \\
& $K_{i, v s p}$ & 0.3 \\
& $K_{d, v s p}$ & 1 \\
\hline
\end{tabular}


Table A3. Comparison of the hydraulic balance and wind energy produced between none VSWT contribution and the proposed VSWT contributions.

\begin{tabular}{|c|c|c|c|c|c|c|c|c|c|c|c|c|}
\hline \multirow{3}{*}{$\begin{array}{c}\text { Prog } \\
\begin{array}{c}\text { VSWT Contribution } \\
\text { and Reserve }\end{array}\end{array}$} & \multicolumn{6}{|c|}{ Annual Difference between Pumped and Turbined Volume } & \multicolumn{6}{|c|}{ Annual Wind Energy } \\
\hline & \multirow{2}{*}{$\begin{array}{l}\mathrm{hm}^{3} \\
\text { None }\end{array}$} & \multicolumn{5}{|c|}{$\begin{array}{l}\text { Variation Respect None VSWT Contribution } \\
\end{array}$} & \multirow{2}{*}{$\begin{array}{l}\text { MWh } \\
\text { None }\end{array}$} & \multicolumn{5}{|c|}{ Variation Respect None VSWT Contribution } \\
\hline & & Inertial & R1 5\% & R1 10\% & Inertial and R1 $5 \%$ & Inertial and R1 10\% & & Inertial & R1 5\% & R1 10\% & Inertial and R1 5\% & Inertial and R1 10\% \\
\hline 1 & -0.22 & $-0.06 \%$ & $0.83 \%$ & $1.72 \%$ & $0.83 \%$ & $1.70 \%$ & 153.69 & $0.28 \%$ & $-3.35 \%$ & $-7.70 \%$ & $-3.34 \%$ & $-7.62 \%$ \\
\hline 2 & -0.46 & $-0.32 \%$ & $0.51 \%$ & $1.33 \%$ & $0.51 \%$ & $1.32 \%$ & 265.91 & $1.76 \%$ & $-2.38 \%$ & $-7.25 \%$ & $-2.41 \%$ & $-7.20 \%$ \\
\hline 3 & -0.56 & $-0.29 \%$ & $0.27 \%$ & $1.03 \%$ & $0.28 \%$ & $1.03 \%$ & 258.59 & $2.00 \%$ & $-1.99 \%$ & $-7.10 \%$ & $-2.04 \%$ & $-7.05 \%$ \\
\hline 4 & -0.16 & $-0.23 \%$ & $0.24 \%$ & $0.90 \%$ & $0.25 \%$ & $0.89 \%$ & 64.69 & $1.87 \%$ & $-2.00 \%$ & $-7.11 \%$ & $-2.07 \%$ & $-7.08 \%$ \\
\hline 5 & -0.07 & $6.25 \%$ & $12.97 \%$ & $18.97 \%$ & $17.91 \%$ & $23.78 \%$ & 446.77 & $1.25 \%$ & $-1.64 \%$ & $-4.39 \%$ & $-1.65 \%$ & $-4.40 \%$ \\
\hline 6 & -0.53 & $0.02 \%$ & $0.93 \%$ & $2.45 \%$ & $1.16 \%$ & $2.55 \%$ & 1017.73 & $0.23 \%$ & $-1.45 \%$ & $-3.74 \%$ & $-1.82 \%$ & $-3.90 \%$ \\
\hline 7 & -0.81 & $-0.93 \%$ & $0.89 \%$ & $2.36 \%$ & $0.97 \%$ & $2.39 \%$ & 1415.20 & $1.72 \%$ & $-1.43 \%$ & $-4.27 \%$ & $-1.56 \%$ & $-4.32 \%$ \\
\hline 8 & -0.16 & $-1.52 \%$ & $0.38 \%$ & $1.84 \%$ & $0.11 \%$ & $1.65 \%$ & 242.86 & $3.13 \%$ & $-0.60 \%$ & $-3.75 \%$ & $-0.03 \%$ & $-3.35 \%$ \\
\hline 9 & 0.04 & $0.32 \%$ & $-2.50 \%$ & $-5.59 \%$ & $-1.58 \%$ & $-4.73 \%$ & 174.89 & $1.63 \%$ & $-1.14 \%$ & $-3.53 \%$ & $-0.30 \%$ & $-2.73 \%$ \\
\hline 10 & 0.19 & $0.56 \%$ & $-1.17 \%$ & $-3.23 \%$ & $-0.72 \%$ & $-2.52 \%$ & 619.44 & $1.47 \%$ & $-0.36 \%$ & $-2.58 \%$ & $0.29 \%$ & $-1.79 \%$ \\
\hline 11 & 0.10 & $-12.94 \%$ & $-22.28 \%$ & $-30.97 \%$ & $-30.13 \%$ & $-38.79 \%$ & 1134.18 & $1.86 \%$ & $-0.97 \%$ & $-3.55 \%$ & $-0.12 \%$ & $-2.71 \%$ \\
\hline 12 & 0.24 & $0.43 \%$ & $-2.18 \%$ & $-4.38 \%$ & $-2.41 \%$ & $-4.71 \%$ & 966.40 & $1.90 \%$ & $-0.07 \%$ & $-2.38 \%$ & $0.54 \%$ & $-1.73 \%$ \\
\hline 13 & 0.17 & $-6.53 \%$ & $-20.69 \%$ & $-30.24 \%$ & $-30.77 \%$ & $-39.44 \%$ & 2560.22 & $1.92 \%$ & $-0.38 \%$ & $-2.78 \%$ & $0.43 \%$ & $-1.88 \%$ \\
\hline 14 & 0.10 & $-0.32 \%$ & $-2.26 \%$ & $-5.97 \%$ & $-2.80 \%$ & $-5.80 \%$ & 537.03 & $1.52 \%$ & $-0.47 \%$ & $-2.81 \%$ & $0.02 \%$ & $-1.98 \%$ \\
\hline 15 & -0.07 & $0.47 \%$ & $6.56 \%$ & $12.77 \%$ & $9.10 \%$ & $14.90 \%$ & 674.91 & $1.93 \%$ & $0.03 \%$ & $-2.13 \%$ & $0.51 \%$ & $-1.54 \%$ \\
\hline 16 & 0.71 & $-0.22 \%$ & $-3.18 \%$ & $-6.86 \%$ & $-3.93 \%$ & $-7.42 \%$ & 1797.57 & $-0.18 \%$ & $-4.07 \%$ & $-8.66 \%$ & $-4.57 \%$ & $-8.92 \%$ \\
\hline 17 & 1.89 & $-0.35 \%$ & $-3.50 \%$ & $-4.88 \%$ & $-4.38 \%$ & $-5.56 \%$ & 5270.96 & $-0.19 \%$ & $-3.87 \%$ & $-5.67 \%$ & $-4.40 \%$ & $-6.02 \%$ \\
\hline 18 & 1.98 & $-0.05 \%$ & $-0.87 \%$ & $-2.71 \%$ & $-1.40 \%$ & $-3.10 \%$ & 6464.26 & $-0.07 \%$ & $-1.30 \%$ & $-3.17 \%$ & $-1.65 \%$ & $-3.44 \%$ \\
\hline 19 & 0.56 & $-0.39 \%$ & $-1.74 \%$ & $-4.02 \%$ & $-2.27 \%$ & $-4.38 \%$ & 2076.92 & $-0.28 \%$ & $-1.80 \%$ & $-3.84 \%$ & $-2.16 \%$ & $-4.08 \%$ \\
\hline 20 & 0.02 & $-2.52 \%$ & $-5.55 \%$ & $-9.61 \%$ & $-8.42 \%$ & $-12.28 \%$ & 151.70 & $0.22 \%$ & $-1.63 \%$ & $-3.85 \%$ & $-1.92 \%$ & $-4.09 \%$ \\
\hline 21 & 0.36 & $0.04 \%$ & $-4.01 \%$ & $-8.20 \%$ & $-4.67 \%$ & $-8.88 \%$ & 1231.97 & $0.32 \%$ & $-3.63 \%$ & $-7.57 \%$ & $-3.95 \%$ & $-7.99 \%$ \\
\hline 22 & 0.34 & $-0.83 \%$ & $-5.03 \%$ & $-9.56 \%$ & $-6.33 \%$ & $-10.64 \%$ & 1226.78 & $-0.51 \%$ & $-4.44 \%$ & $-8.74 \%$ & $-5.52 \%$ & $-9.59 \%$ \\
\hline Annual total & 3.69 & $-0.76 \%$ & $-6.75 \%$ & $-12.53 \%$ & $-8.76 \%$ & $-14.18 \%$ & 28752.66 & $0.51 \%$ & $-2.05 \%$ & $-4.57 \%$ & $-2.20 \%$ & $-4.60 \%$ \\
\hline
\end{tabular}



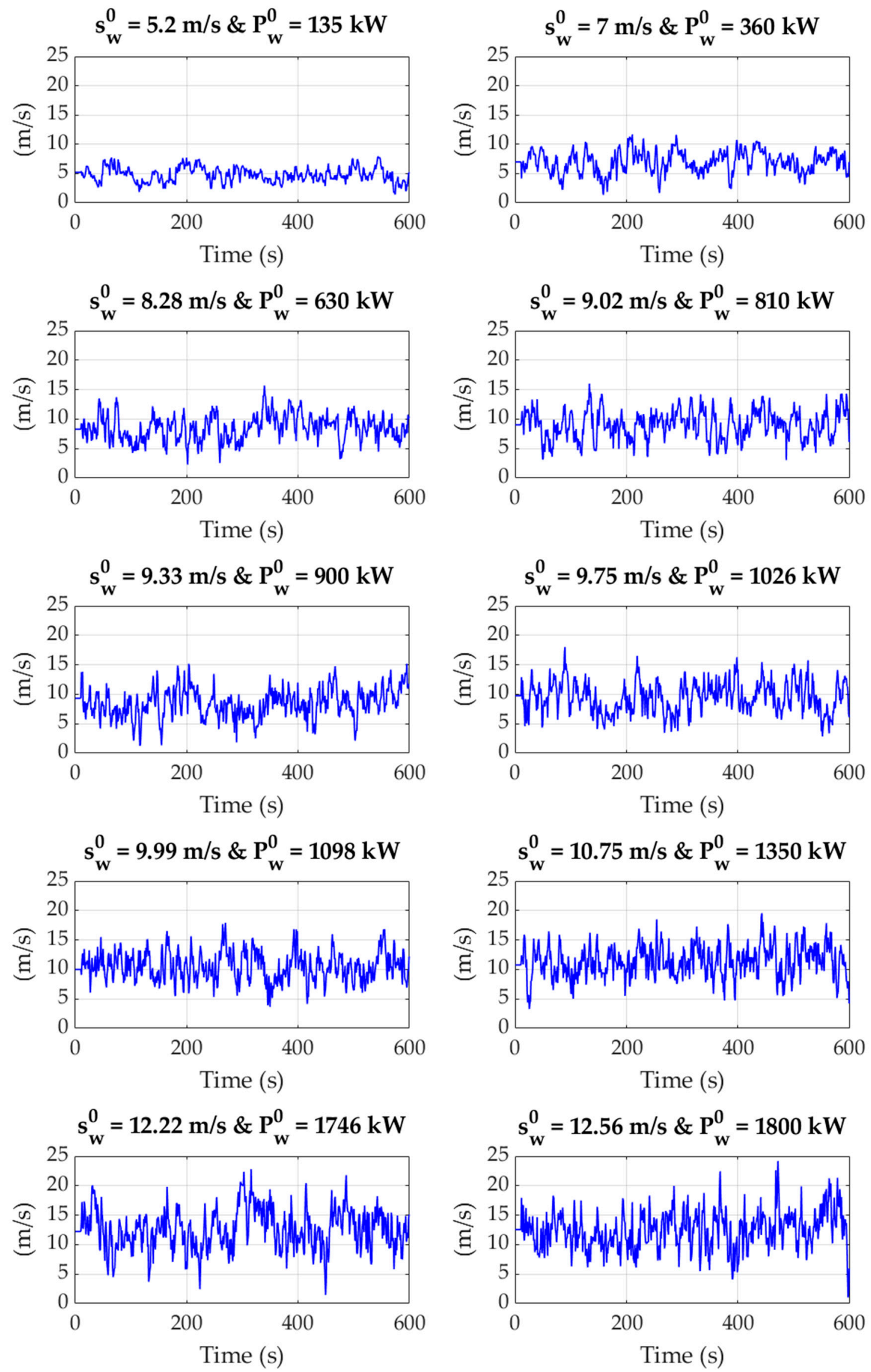

Figure A1. Ten generated wind speed signals. 


\section{References}

1. Denholm, P.; Ela, E.; Kirby, B.; Milligan, M. The Role of Energy Storage with Renewable Electricity Generation; National Renewable Energy Laboratory: Golden, CO, USA, 2010.

2. Singh, S.; Singh, M.; Chandra Kaushik, S. Feasibility study of an islanded microgrid in rural area consisting of PV, wind, biomass and battery energy storage system. Energy Convers. Manag. 2016, 128, 178-190. [CrossRef]

3. Eras-Almeida, A.; Egido-Aguilera, M. Hybrid renewable mini-grids on non-interconnected small islands: Review of case studies. Renew. Sustain. Energy Rev. 2019, 116, 1-20. [CrossRef]

4. Kaldellis, J.; Kavadias, K.; Christinakis, E. Evaluation of the wind-hydro energy solution for remote islands. Energy Convers. Manag. 2001, 42, 1105-1120. [CrossRef]

5. Caralis, G.; Zervos, A. Analysis of the combined use of wind and pumped storage systems in autonomous Greek islands. IET Renew. Power Gener. 2007, 1, 49-60. [CrossRef]

6. Suul, J.A.; Uhlen, K.; Undeland, T. Wind power integration in isolated grids enabled by variable speed pumped storage hydropower plant. In Proceedings of the 2008 IEEE International Conference on Sustainable Energy Technologies, Singapore, 24-27 November 2008.

7. Bueno, C.; Carta, J. Wind powered pumped hydro storage systems, a means of increasing the penetration of renewable energy in the Canary Islands. Renew. Sustain. Energy Rev. 2006, 10, 312-340. [CrossRef]

8. Martínez-Lucas, G.; Sarasúa, J.I.; Sánchez-Fernández, J.Á. Power-frequency control of hydropower plants with long penstocks in isolated systems with wind generation. Renew. Energy 2015, 83, 245-255. [CrossRef]

9. Iglesias, G.; Carballo, R. Wave resource in El Hierro- an island towards energy self-sufficiency. Renew. Energy 2011, 36, 689-698. [CrossRef]

10. Gao, W.; Wu, Z.; Wang, J.; Gu, S. A review of inertia and frequency control technologies for variable speed wind turbines. In Proceedings of the 2013 25th Chinese Control and Decision Conference (CCDC), Guiyang, China, 25-27 May 2013.

11. Albadi, M.; El-Saadany, E. Overview of wind power intermittency impacts on power systems. Electr. Power Syst. Res. 2010, 80, 627-632. [CrossRef]

12. Attya, A.; Domingues-Garcia, J.; Onaya-Lara, O. A review on frequency support provision by wind power plants: Current and future challenges. Renew. Sustain. Energy Rev. 2018, 81, 2071-2087. [CrossRef]

13. O'Sullivan, J.; Rogers, A.; Flynn, D.; Smith, P.; Mullane, A.; O'Malley, M. Studying the maximum instantaneous non-synchronous generation in an island system-Frequency stability challenges in ireland. IEEE Trans. Power Syst. 2014, 29, 2943-2951. [CrossRef]

14. Ela, E.; Brooks, D. Active Power Control from Wind Power. 2011. Available online: https://www.nrel.gov/ docs/fy11osti/51488.pdf (accessed on 4 March 2018).

15. Aziz, A.; Aman, T.O.; Stojcevski, A. Frequency regulation capabilities in wind power plant. Sustain. Energy Technol. Assess. 2018, 26, 47-76. [CrossRef]

16. Mullane, A.; O'Malley, M. The Inertial Response of Induction-Machine-Based Wind Turbines. IEEE Trans. Power Syst. 2005, 20, 1496-1503. [CrossRef]

17. Morren, J.; Pierik, J.; de Haan, S.W. Inertial response of variable speed wind turbines. Electr. Power Syst. Res. 2006, 76, 980-987. [CrossRef]

18. Mauricio, J.M.; Marano, A.; Gómez-Expósito, A.; Martínez Ramos, J.L. Frequency Regulation Contribution Through Variable-Speed Wind Energy Conversion System. IEEE Trans. Power Syst. 2009, 24, 173-180. [CrossRef]

19. Sarasúa, J.I.; Martínez-Lucas, G.; Lafoz, M. Analysis of alternative frequency control schemes for increasing renewable energy penetration in El Hierro Island power system. Electr. Power Energy Syst. 2019, 113, 807-823. [CrossRef]

20. Feltes, J.W.; Fernandes, B.S.; Senthil, J. Development of a Controller to Provide Primary Frequency Response Capability for a Wind Farm; National Harbor: Potomac River, MD, USA, 2014.

21. De Almeida, R.; Castronuovo, E.D.; Lopes, J.A.P. Optimum generation control in wind parks when carrying out system operator requests. IEEE Trans. Power Syst. 2006, 21, 718-725. [CrossRef]

22. Courtecuisse, V.; Robyns, B.; Francois, B.; Petit, M.; Deuse, J. Variable Speed Wind Generators Participation in Primary Frequency Control. Wind Eng. 2008, 32, 299-318. [CrossRef]

23. El Mokadem, M.; Courtecuisse, V.; Saudemont, C.; Robyns, B.; Deuse, J. Experimental study of variable speed wind generator contribution to primary frequency control. Renew. Energy 2009, 34, 833-844. [CrossRef] 
24. Ma, H.; Chowdhury, B. Working towards frequency regulation with wind plants: Combined control approaches. IET Renew. Power Gener. 2010, 4, 308-316. [CrossRef]

25. Margaris, I.D.; Papathanassiou, S.A.; Hatziargyriou, N.D.; Hansen, A.D.; Sorensen, P. Frequency control in autonomous power systems with high wind power penetration. IEEE Trans. Sustain. Energy 2012, 3, 189-199. [CrossRef]

26. Wang, Y.; Delille, G.; Bayem, H.; Guillaud, X.; Francois, B. High wind power penetration in isolated power systems-Assessment of wind inertial and primary frequency responses. IEEE Trans. Power Syst. 2013, 28, 2412-2420. [CrossRef]

27. Wang, Z.; Wu, W. Coordinated Control Method for DFIG-Based Wind Farm to Provide Primary Frequency Regulation Service. IEEE Trans. Power Syst. 2018, 33, 2644-2659. [CrossRef]

28. Fernández-Muñoz, D.; Pérez-Díaz, J.I.; Chazarra, M. A two-stage stochastic optimisation model for the water value calculation in a hybrid diesel/wind/pumped-storage power system. IET Renew. Power Gener. 2019, 13, 2156-2165. [CrossRef]

29. Martínez-Lucas, G.; Sarasúa, J.I.; Sánchez-Fernández, J.Á. Frequency Regulation of a Hybrid Wind-Hydro Power Plant in an Isolated Power System. Energies 2018, 11, 239. [CrossRef]

30. Mansoor, S.; Jones, D.; Bradley, F.; Jones, G. Reproducing oscillatory behaviour of a hydroelectric power station by computer simulation. Control Eng. Pract. 2000, 8, 1261-1272. [CrossRef]

31. Clark, K.; Miller, N.W.; Sanchez-Gasca, J.J. Modeling of GE Wind Turbine-Generators for Grid Studies; General Electric International, Inc.: Schenectady, NY, USA, 2010.

32. Zhao, S.; Nair, N.-K. Assessment of wind farm models from a transmission system operator perspective using field measurements. IET Renew. Power Gener. 2011, 5, 455-464. [CrossRef]

33. Pérez-Díaz, J.I.; Wilhelmi Ayza, J.R.; Galaso Bajo, I.; Fraile-Ardanuy, J.; Sánchez-Fernández, J.Á.; Castaneda Cabrero, O.; Sarasúa Moreno, J.I. Dynamic response of hydro power plants to load variations for providing secondary regulation reserves considering elastic water column effects. Prz. Elektrotech. 2012, 88, 159-163.

34. Pérez-Díaz, J.I.; Sarasúa, J.I.; Wilhelmi, J.R. Contribution of a hydraulic short-circuit pumped-storage power plant to the load-frequency regulation of an isolated power system. Electr. Power Energy Syst. 2014, 62, 199-211. [CrossRef]

35. Wood, A.; Wollenberg, B. Power Generation Operation and Control, 2nd ed.; John Wiley \& Sons: New York, NY, USA, 1996.

36. Martínez-Lucas, G.; Sarasúa, J.I.; Sánchez-Fernández, J.Á. Eigen analysis of wind-hydro joint frequency regulation in an isolated power system. Electr. Power Energy Syst. 2018, 103, 511-524. [CrossRef]

37. Novaes Menezes, E.J.; Araújo, A.M.; da Silva, N.S.B. A review on wind turbine control and its associated methods. J. Clean. Prod. 2018, 174, 945-953. [CrossRef]

38. De España, R.E. P.O. 2.2: Cobertura de la demanda, programación de la generación y altas en el despacho económico. Bol. Of. Del Estado 2019, 20, 137787-138065.

39. Van der Hoven, I. Power spectrum of horizontal wind speed in the frequency range from 0.0007 to 900 cycles per hour. J. Meteorol. 1957, 14, 160-164. [CrossRef]

40. Leithead, W.; de la Salle, S.; Reardon, D. Role and objectives of control for wind turbines. IEE Proc. C Gener. Trans. Distrib. 1991, 138, 135-148. [CrossRef]

41. Nichita, C.; Luca, D.; Dakyo, B.; Ceanga, E. Large band simulation of the wind speed for real time wind turbine simulators. IEEE Trans. Energy Convers. 2002, 17, 523-529. [CrossRef]

42. International Electrotechnical Comission. Wind Energy Generation Systems-Part 1: Design Requirements, 4th ed.; International Electrotechnical Comission: Geneva, Switzerland, 2019.

43. Marrero Quevedo, A.; Medina Domínguez, E.J.; de León Izquier, J.M.; de León, R.C.; Santos Arozarena, P.; Gil Moreno, J.; Castañeda Quintero, A.; González Hernández, J. Gorona del Viento Wind-Hydro Power Plant. In Proceedings of the 3rd International Hybrid Power Systems Workshop, Tenerife, Spain, 8-9 May 2018.

44. Montgomery, J. Confidence Intervals with the $\mathrm{z}$ and $\mathrm{t}$-Distributions. 2016. Available online: https: //pages.wustl.edu/montgomery/articles/2757 (accessed on 1 April 2020).

(C) 2020 by the authors. Licensee MDPI, Basel, Switzerland. This article is an open access article distributed under the terms and conditions of the Creative Commons Attribution (CC BY) license (http://creativecommons.org/licenses/by/4.0/). 